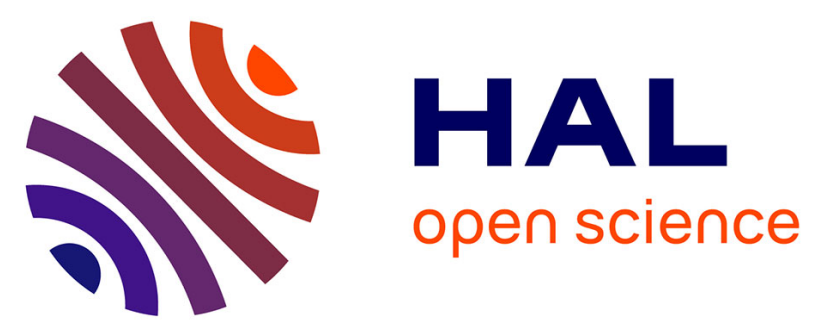

\title{
On the effects of opposed flow conditions on non-buoyant flames spreading over polyethylene-coated wires - Part I: Spread rate and soot production
}

\author{
Augustin Guibaud, Jean-Marie Citerne, Jean-Louis Consalvi, Guillaume \\ Legros
}

\section{To cite this version:}

Augustin Guibaud, Jean-Marie Citerne, Jean-Louis Consalvi, Guillaume Legros. On the effects of opposed flow conditions on non-buoyant flames spreading over polyethylene-coated wires - Part I: Spread rate and soot production. Combustion and Flame, 2020, 221, pp.530-543. 10.1016/j.combustflame.2020.07.044 . hal-02985715

\section{HAL Id: hal-02985715 \\ https: / hal.sorbonne-universite.fr/hal-02985715}

Submitted on 2 Nov 2020

HAL is a multi-disciplinary open access archive for the deposit and dissemination of scientific research documents, whether they are published or not. The documents may come from teaching and research institutions in France or abroad, or from public or private research centers.
L'archive ouverte pluridisciplinaire HAL, est destinée au dépôt et à la diffusion de documents scientifiques de niveau recherche, publiés ou non, émanant des établissements d'enseignement et de recherche français ou étrangers, des laboratoires publics ou privés. 


\title{
On the effects of opposed flow conditions on non-buoyant flames spreading over polyethylene-coated wires - Part I: spread rate and soot production
}

\author{
Augustin Guibaud ${ }^{\mathrm{a}, *}$, Jean-Marie Citerne ${ }^{\mathrm{a}}$, Jean-Louis Consalvi ${ }^{\mathrm{b}}$, \\ Guillaume $\operatorname{Legros}^{\mathrm{a}}$ \\ ${ }^{a}$ Sorbonne Université, Centre National de la Recherche Scientifique, UMR 7190, Institut \\ Jean Le Rond d'Alembert, F-75005 Paris, France \\ ${ }^{b}$ Aix-Marseille Université, IUSTI/UMR CNRS 7343, 5 rue E. Fermi, 13453 Marseille \\ Cedex 13, France
}

\section{Abstract}

In microgravity, the extended time scales associated with the absence of buoyancy lead to peculiar flame features that are likely to affect the risk associated with flame spread in the case of a spacecraft fire. Investigating a non-buoyant flame spreading over the polyethylene coating of an electrical wire in an opposed laminar flow, recent studies especially evidenced and quantified the major role of soot in the radiative heat transfer, which affects local quenching at the flame tip as well as heat feedback from the flame to the coating. Consequently, the control of soot production in such a flame needs to be explored. In the present paper, the role of basic flow features, i.e. oxygen content, flow velocity, and ambient pressure, is documented. Conducted in parabolic flights, a set of 142 experiments spreads over 91 flow conditions,

\footnotetext{
*Corresponding author

Email addresses: augustin.guibaud@sorbonne-universite.fr (Augustin Guibaud ), jean-marie.citerne@sorbonne-universite.fr (Jean-Marie Citerne), jean-louis.consalvi@univ-amu.fr (Jean-Louis Consalvi), guillaume.legros@sorbonne-universite.fr (Guillaume Legros)
} 
with oxygen content ranging from $18 \%$ to $21 \%$, flow velocity kept between $100 \mathrm{~mm} . \mathrm{s}^{-1}$ and $200 \mathrm{~mm} . \mathrm{s}^{-1}$, and pressure ranging from $51 \mathrm{kPa}$ to $142 \mathrm{kPa}$. The implementation of the Broadband Modulated Absorption/Emission (BMAE) technique allows the fields of soot temperature and volume fraction to be measured within the spreading flames.

The flame spread rate is thus shown to be an increasing function of oxygen content, but is independent of flow velocity and pressure. Concomitantly, both oxygen content and flow velocity affect soot production residence time, while pressure has a marginal impact on it. Maximum soot volume fraction is a function of all three parameters. Complementing these results with a scaling analysis, soot production rate is third-order in pressure, and very sensitive to oxygen content. An increase in flow velocity promotes two competitive processes with respect to maximum soot volume fraction, i.e. a reduction in residence time and an increase in flame temperature. A numerical model supports the experimental finding that the latter phenomenon prevails, hence that maximum soot volume fraction increases with flow velocity. These conclusions will serve as basis for upcoming quenching and radiative heat feedback analysis.

Keywords: microgravity, flame spread, soot, ambient conditions, optical diagnostics 


\section{Nomenclature}

A cross-sectional area $\left(\mathrm{m}^{2}\right)$

C constant of proportionality (-)

$\mathrm{c}_{p} \quad$ Heat capacity $\left(\mathrm{J} . \mathrm{kg}^{-1} \cdot \mathrm{K}^{-1}\right)$

D Mass diffusivity $\left(\mathrm{m}^{2} \cdot \mathrm{s}^{-1}\right)$

$f_{s} \quad$ Soot volume fraction (-)

$F_{s} \quad$ Radially-integrated soot volume fraction $f_{s}\left(\mathrm{~m}^{2}\right)$

$\mathrm{g}_{0} \quad$ Gravitational acceleration $\left(\mathrm{m} . \mathrm{s}^{-2}\right)$

$\mathrm{I}, \mathrm{I}_{0} \quad$ Broadband radiative intensity $\left(\mathrm{W} \cdot \mathrm{m}^{-2} \cdot \mathrm{sr}^{-1}\right)$

$\mathrm{k} \quad$ Thermal conductivity $\left(\mathrm{W} \cdot \mathrm{m}^{-1} \cdot \mathrm{K}^{-1}\right)$

L Length (m)

$\dot{m}_{F} \quad$ Pyrolysis mass flow rate $\left(\mathrm{kg} . \mathrm{s}^{-1}\right)$

$\mathrm{P} \quad$ Pressure $(\mathrm{kPa})$

$P_{s} \quad$ perimeter of a section of the sample $(\mathrm{m})$

$\dot{Q} \quad$ heat flux $\left(\mathrm{W} . \mathrm{m}^{-2}\right)$

$\mathrm{r} \quad$ radial coordinate $(\mathrm{m})$

S oxidizer/fuel mass ratio (-)

Sc Schmidt Number (-)

t Time (s)

T Temperature $(\mathrm{K})$

u Velocity $\left(\mathrm{m} . \mathrm{s}^{-1}\right)$

$\mathrm{u}_{p} \quad$ spread rate $\left(\mathrm{m} . \mathrm{s}^{-1}\right)$

$\mathrm{x}$ mole fraction (-)

Y Mass fraction (-)

$\mathrm{z} \quad$ streamwise coordinate $(\mathrm{m})$ 
$\beta \quad$ Logarithmic regression coefficients (-)

$\delta \quad$ Flame width $(\mathrm{m})$

$\Delta \mathrm{h}_{c}$ Heat of combustion $\left({\left.\mathrm{J} . \mathrm{kg}^{-1}\right)}^{-1}\right.$

$\kappa \quad$ Spectral absorption coefficient $\left(\mathrm{m}^{-1}\right)$

$\lambda \quad$ Wavelength (m)

$\mu \quad$ Dynamic viscosity $\left(\mathrm{kg} \cdot \mathrm{m}^{-1} \cdot \mathrm{s}^{-1}\right)$

$\nu \quad$ Kinematic viscosity $\left(\mathrm{m}^{2} \cdot \mathrm{s}^{-1}\right)$

$\rho \quad$ Density $\left(\mathrm{kg} . \mathrm{m}^{-3}\right)$

$\tau \quad$ Thickness $(\mathrm{m})$

$\dot{\omega}_{S P}^{\prime \prime \prime} \quad$ Soot production rate $\left(\mathrm{kg} \cdot \mathrm{m}^{-3} \cdot \mathrm{s}^{-1}\right)$ 


\begin{tabular}{ll}
\multicolumn{2}{c}{ Subscript } \\
$\infty$ & Ambient \\
core & Metallic core \\
$\mathrm{F}$ & Fuel surface \\
$f l$ & Flame \\
$\mathrm{L}_{s}$ & Soot formation length \\
$\mathrm{O}_{2}$ & molecular oxygen \\
res & Residence \\
$\mathrm{s}$ & Soot \\
$\mathrm{S}$ & Oxidizer/fuel mass ratio \\
$\mathrm{SF}$ & Solid Fuel \\
$\mathrm{u}_{p}$ & Relative to spread rate \\
wire & Coated wire \\
$\lambda$ & At a given wavelength
\end{tabular}

Superscript

$1+\mathrm{S}$ Relative to the oxidizer/fuel mass ratio

P Relative to pressure

$\mathrm{u}_{\infty} \quad$ Relative to ambient flow velocity 


\section{Introduction}

Should a fire start in the confined environment of a spacecraft, the consequences are likely to be dramatic. Damages to vital equipment and pollution of the atmosphere above breathing levels may pose a threat to the success of a mission, or worse, to the safety of the astronauts. As an illustration, a short circuit in an oxygen tank caused the Apollo 13 incident in 1970 [1], heavy smoke provoked emergency procedures on three occasions in 1971, 1977, and 1978 aboard spacecraft from the Salyut program [2, 3], and five accounts of electrical failures were reported in the NASA Orbiter Fleet from 1983 to 1992 [4]. Though no major fire incident has been reported in space exploration since 1997, present mitigation strategies in spacecraft rely on the possibility of a fast resupply mission from the Earth, which is not workable in the context of deep space exploration. The present state of spacecraft technologies still requires the use of flammable material in vital equipment. Such is the case of lithium perchlorate in oxygen generators [5], or polyethylene-based panels presently considered for radiation shielding in the context of deepspace exploration [6]. Understanding the corresponding material behaviour in a fire in weightlessness is thus crucial.

Material flammability and flame propagation in microgravity over various samples have thus received widespread attention since the 1990s to prepare for long range missions [7-12]. Material flammability tests based on pass/fail

criteria are extrapolated from the analysis of extinction boundaries [13], and extensive work has led to a fine understanding of the unique quenching and blow-off mechanisms reported in microgravity [14-16]. Systematic characterisation of the impact of sample geometry and ambient flow conditions on 
flammability limits has also highlighted the increased risk of flame propagation in the absence of buoyancy $[14,17]$. In the meantime, spherical thermal expansion increases the probability to ignite adjacent surfaces [18], and experiments have shown that an external radiant flux supports combustion in the absence of buoyancy to a greater extent than usually reported on Earth [17]. Thus, a fire event in a spacecraft could begin and be sustained in situations unpredicted at normal gravity.

Yet, while most major incidents reported in spacecraft referred to smoke issues, there is a surprisingly limited amount of data on the impact of microgravity on smoke production in a spreading flame, knowing that smoke inhalation is responsible for a vast majority of casualties in accidental fires on the ground [19]. During the first long-duration experiments in the Glovebox Facility of the Space Shuttle, Greenberg et al. reported the formation of substantial soot agglomerates in flames established over Nickel-Chrome ( $\mathrm{NiCr}$ ) metallic wires coated with low-density polyethylene (LDPE) [7]. This observation was made in both concurrent and opposed flow configurations. Microscopic analysis showed that the collected soot featured a unique morphology, with primary particles three times as big as those obtained under the same flow conditions in ground-based facilities. Such observations correlated well with simultaneous smoke point and radiation measurements over burners in microgravity [20] since high soot loads associated with the extended residence time in the fuel-rich side of the diffusion flame lead to an increase in flame radiations [21,22] which tends to trigger quenching at the flame tip. Studies in spreading situation, away from the extinction limit [23], showed the presence of radiant soot particles in the hot region of a flame in 
quiescent atmosphere, and experiments in a laminar concurrent or opposed oxidizer flow has confirmed the presence of intensely-radiating soot particles in atmospheric conditions similar to those adopted for space exploration $[8,9]$. In addition to the role of soot in the local quenching at the flame tip, Citerne et al. [10] identified the correlation between heavy soot loads and unusual acceleration of concomitant flame spreads over electrical wires in microgravity. The latter was attributed to flame interactions that the radiative transfer enhanced by the high soot load sustains especially in microgravity. Consequently, probing flames in microgravity to quantify soot properties in the absence of buoyant flow is crucial to launch safe space exploration missions. In the meantime, microgravity situations provide a unique opportunity to study soot particles at long residence time. Space Shuttle experiments provided long-duration observations of soot volume fraction, temperature, and primary particles dimensions over an ethylene burner in still air, at various fuel flow and pressure levels [24]. Results showed that the observed soot particles comply with the hypotheses of the Rayleigh regime, and that soot volume fraction soars with pressure. However, from a fire safety perspective, such analysis does not take into consideration the modifications in burning rates induced by microgravity.

While three-dimensional steady flames can be probed by optical techniques [25], the configuration related to the aforementioned electrical wire also enables the implementation of such non-intrusive techniques in axisymmetric spreading flames [26, 27]. Thus, Guibaud et al. [27] focused on flame spread over a single electrical wire. After a thorough evaluation of the performances of the Broadband Modulated Absorption/Emission technique (B-MAE) on 
an academic burner configuration at normal gravity [26], the authors successfully set the technique in a rig designed for parabolic flights and probed the flame spreading in an opposed flow over the polyethylene coating of an electrical wire in microgravity [27]. Doing so, the authors could measure the fields of local soot temperature and volume fraction within the flame spreading at a steady rate. As a result, they could access the field of local radiative balance and ultimately the distribution of the radiative flux to the wire attributed to soot. A complementary numerical simulation of the configuration showed that the contribution of soot exceeds two thirds of the overall radiative flux to the wire [28].

The present study focuses on providing an experimental characterization of the influence of ambient flow conditions on soot production in the aforementioned spreading flame. To this end, the measurements enabled by the B-MAE technique are repeated for different oxygen contents, flow velocities and pressure levels to especially identify the effects of these parameters on the spread rate, the soot production residence time, and the maximum soot volume fraction.

\section{Initial observations and associated issues}

Experiments conducted in parabolic flights and following a protocol that is described in Section 3 have led to observations that question the impact of pressure on flame spread over cylindrical samples in microgravity. Set into a diluted oxidizer stream composed of $19 \%$ oxygen and $81 \%$ nitrogen in volume and flowing parallel to the sample's axis at a free stream velocity of

$\mathrm{u}_{\infty}=150 \mathrm{~mm} \cdot \mathrm{s}^{-1}$, polyethylene coated wires were ignited at three different 
pressure levels of $70.9 \mathrm{kPa}, 101.3 \mathrm{kPa}$, and $141.8 \mathrm{kPa}$. These wires consisted of a $0.5 \mathrm{~mm}$ in diameter nickel-chrome core coated with a $0.3 \mathrm{~mm}$ thick lowdensity polyethylene (LDPE) layer. Once the flame spread is established at a steady rate over the coating in an opposed flow configuration, early observations which highlight the core concerns of the present paper are carried out as illustrated in Fig. 1.

Direct visualisations show that the flame brightness increases with pressure. In addition, the flames at 70.9 and $101.3 \mathrm{kPa}$ are non-smoking whereas that at $141.8 \mathrm{kPa}$ is smoking. This shows that the Smoke point transition [22, 29, 30], which corresponds to a radiative quenching at the flame trailing edge [29, 31], occurs between $101.3 \mathrm{kPa}$ and $141.8 \mathrm{kPa}$. The corresponding soot volume fraction and temperature radial profiles at four locations along the wire, obtained using the Broadband Modulated Absorption/Emission (BMAE) technique [26], are also displayed in Fig. 1. It can be observed that, for a given location along the wire axis, an increase in pressure leads to a dramatic increase in soot volume fraction. Interestingly, this finding is in agreement with the trend identified by Karatas and Gülder in laminar coflow diffusion flames at normal gravity [32]. Additionally, temperature decreases as pressure increases, especially in the vicinity of the flame tip, due to enhanced radiative losses.

In this context, comparing soot volume fraction at given distances from the flame leading edge for different pressures can be questioned since different characteristic time scales for soot production can be encountered. The residence time depends on flame structure and, in turn, on flame spread and pyrolysis rates, that can be influenced by pressure [33]. As a consequence, a 
comprehensive understanding of the effects of pressure on the flame spread characteristics is required to quantify the effects of pressure on soot production. The same questions arise for the other ambient parameters considered in the present study, namely the oxidizer flow rate and oxygen content. In the following, experimental investigations conducted in parabolic flights document the impact of the oxidizer flow rate, oxidizer oxygen content, and pressure on the flame spread characteristics. The fuel injection rate is computed from the measured flame spread rate, and the flame length is computed to account for the flow characteristic times within the flame. Within the limits of the B-MAE technique, soot related fields are measured. These observations are complemented by a theoretical analysis, that uses experimental data to support the main hypotheses.

\section{Experiments and diagnostics}

\subsection{Experimental setup}

Using the Detection of Ignition And Mitigation Onboard for Non-Damaged Spacecrafts (DIAMONDS) rig that has been extensively detailed in Ref. [10], the experiments are conducted aboard the Novespace A310 ZeroG airplane, a facility that specifically operates parabolic flights. Every parabola provides a 22s long sequence of microgravity with an accuracy level of $10^{-2} \mathrm{~g}_{0}\left(\mathrm{~g}_{0}=9.81\right.$ $\left.\mathrm{m} . \mathrm{s}^{-2}\right)$. The central element of this setup is a cylindrical combustion chamber with an inner diameter of $190 \mathrm{~mm}$. A laminar oxidizer flow can be established in this combustion chamber, with controlled oxygen content, pressure, and flow velocity. Cylindrical samples, with a length of $150 \mathrm{~mm}$ and consisting of a $0.5 \mathrm{~mm}$ Nickel-Chrome metallic core coated by a $0.3 \mathrm{~mm}$ thick layer 
of LDPE, are located along the chamber axis. Prior to any microgravity period, the sample present in the chamber is ignited using an incandescent Kanthal wire. Throughout the range of experimental conditions investigated, such sample dimensions allow an opposed-flow flame to reach a steady propagation rate within the microgravity period of time [27]. In the following, experimental characterization of a steady propagation relies especially on a constant flame spread rate, a constant flame length, and a constant molten polyethylene droplet volume (see the frames in Fig. 1), as detailed in Ref. [27]. It is worth noticing that concurrent flow propagations investigated over the same wires could only reach a steady spread rate at low pressure $(\mathrm{P}<$ $90 \mathrm{kPa})$ and low oxygen content $\left(x_{\mathrm{O}_{2}}<18 \%\right)$ conditions. Reports of steady concurrent spread over similar samples in parabolic flights at higher oxygen content or higher pressure usually neglect the variations in molten insulation droplet volume, though it highlights an absence of heat transfer equilibrium [11]. Thus, this study does not explore concurrent spread configurations.

Images of the flame spread such as those displayed in Fig. 1 are captured using a JAI AT-140CL digital 12-bit tri-CCD camera, equipped with a telecentric lens, to restrict the light collection to beams parallel to the optical axis. This Edmund Optics 0.064X, 1/1.8" GoldTL Telecentric lens has a telecentricity below $0.02^{\circ}$ within the visible range. Given the dimensions of the system, this leads to a signal overlap of about $0.1 \%$ at the flame location, which is negligible compared to the bias associated with the experimental noise. Light is collected by three $512 \times 1396$ pixels $^{2}$ CCD array over three spectral bands, ranging from $400 \mathrm{~nm}$ to $510 \mathrm{~nm}$ (blue), $480 \mathrm{~nm}$ to $600 \mathrm{~nm}$ (green), and $570 \mathrm{~nm}$ to $700 \mathrm{~nm}$ (red), respectively. The spectral sen- 
sitivity over each band has been carefully established, using a THR 1000 monochromator with a $5 \mathrm{~nm}$ step. The pixel resolution is $72.6 \mu \mathrm{m}$ for each spectral band, and images are acquired at a rate of $39.06 \mathrm{fps}$. To perform the B-MAE technique, images of the flame with and without a backlighting are required. As a result, both the sample to be burnt and a backlighting screen are aligned on the camera optical axis. To generate such a backlight that uniformly illuminates the sample, the light delivered by a set of LEDs is reflected on a white diffusive screen. This backlighting is alternatively set on and off by a digital pulse generator that also triggers the start of the CCD exposure. Thus, the sequence of frames recorded by the frame grabber along the microgravity period of time consists of a set of pairs (typically 500), each imaging consecutively the flame with and without the backlight.

As highlighted above, exploring operational parameters such as pressure and oxygen content leads to significant evolutions of the flame brightness and optical thickness. For this reason, the main settings driving the dynamics of the B-MAE technique needed to be made adjustable. As an original development of the experimental setup designed for the present study, the backlight that used to be produced by only white LEDs [26] has now been added sets of blue, green, and red LEDs. In addition, the current powering each of these four sets of LEDs can be adjusted independently. As for the CCDs spectral sensitivity, a careful spectral profiling has been conducted for every setting of the backlighting. Since the exposure time and the gain of each CCD can also be set separately, the dynamics of the blue, green, and red signals can be optimized for every set of experimental conditions. Typically, for every spectral range, about 2,000 levels of intensity (a.u.) are devoted to the mea- 
surements of the backlighting mean intensity and its partial absorption while the flame emission rate is captured over the remaining part (2095 levels). It is worth mentioning here that a MATLAB program has been elaborated to rapidly process the frames recorded within a parabola. This allows the next set of adjustments to be prescribed before the coming parabola.

Less demanding techniques such as two or three color pyrometry [34] could have also been implemented for certain conditions, especially for flames exhibiting lower optical thickness [35]. However, B-MAE measurements were systematically performed throughout the range of conditions investigated to preserve the consistency of the methodology.

\subsection{Measurement of spread rate and flame length}

Flame spread rate, $\mathrm{u}_{p}$, is tracked using the technique described in Ref. [27], summarized as follows. As the flame spreads and heats up solid LDPE, a droplet of molten insulation is formed [36] (see Fig. 1). In the absence of dominant gravitational forces, this droplet of molten insulation is maintained on the wire by surface tension, and retracts along the wire. At first, the volume of the droplet increases, and, for the conditions investigated in the present study, reaches a steady value in the limited amount of time available within a parabola. The flame is assumed to spread at a steady rate once the dimensions of the molten insulation droplet, the visible flame length, and the rate of the flame front displacement reach a steady state value. The flame spread rate is then assumed to match the molten insulation receding rate. 


\section{3. $B$-MAE processing}

The Spectral Modulated Absorption Emission (S-MAE) technique and its extension to broadband light operation (B-MAE) have been extensively detailed in Refs. [37] and [26], respectively. The basics of the B-MAE technique are here briefly recalled. This technique is shown to provide simultaneously up to 19 two-dimensional fields per second of soot temperature and volume fraction in axisymmetric laminar non-premixed flames with uncertainty levels lower than $\pm 50 \mathrm{~K}$ and $\pm 1 \mathrm{ppm}$ [28], with a spatial resolution of 72.6 $\mu \mathrm{m}$. Due to the additional settings that are now enabled as mentioned in Section 3.1, these features have been maintained over the range of parameters investigated in the present study.

The optical setup equipping DIAMONDS has been specifically designed to implement the BMAE technique [26, 27]. This technique considers soot selfabsorption along the line-of-sight, which is essential to get accurate measurements at higher pressure and/or higher oxygen content, where the opticallythin approximation ceases to be valid. The importance of the self-absorption can be quantified by considering the minimum of the transmission ratio $\left(I / I_{0}\right)$, with $I$ being the intensity of the backlight collected by the red CCD in the presence of the flame and $I_{0}$ the intensity of the backlight collected by the same CCD in the absence of the flame. For the three conditions considered in Section 2, this minimum is 0.91 at $70.9 \mathrm{kPa}, 0.70$ at $101.3 \mathrm{kPa}$, and 0.54 at $141.8 \mathrm{kPa}$. Thus, no more than $9 \%$ of the signal is absorbed through the flame at lower pressure, but up to $46 \%$ at higher pressure.

Within the visible spectral range $(400 \mathrm{~nm}<\lambda<700 \mathrm{~nm})$, the flame is consid-

ered as an emitting, absorbing, but non-scattering medium. For the laminar 
ethylene-based diffusion flames studied, the radiative spectrum in the visible range is governed by the continuum radiation from soot [38]. Though debatable near the spectral ranges of emission of $\mathrm{CO}_{2}, \mathrm{H}_{2} \mathrm{O}, \mathrm{OH}$, and radical species of the flame, it is a reasonable assumption in the upper part of the visible spectrum $(\lambda>500 \mathrm{~nm})$. In such a configuration, the Radiative Transfer Equation (RTE) can be integrated along the optical pathways captured by the camera [39]. When the backlight is off, the energy accumulated on a pixel of a camera CCD during the exposure time is mainly attributed to the steady impinging flux emitted by the flame, integrated over the spectral transmission range of the CCD concerned. When the backlight is on, the energy accumulated on the same pixel is complemented by the transmitted energy of the non-coherent backlight. Imaging consecutively the flame with and without the backlight allows measurement of the difference between both frames, which corresponds to the experimental integrated transmission field. Assuming that primary soot particles radiate within the Rayleigh limit of the Mie theory, and incorporating a model of spectral dependency of the local spectral absorption coefficient $\kappa_{\lambda}$ [40], this transmission field can be related to the soot volume fraction field. As the information is integrated over the line-of-sight, the measurements need to be combined with a deconvolution procedure to compute the local fields. To this end, an onion-peeling method combined with a Tikhonov regularization is employed, as detailed in Ref. [41]. The local soot volume fraction field, $f_{s}(r, z)$, can then be inferred.

The frame captured in the absence of backlight is then processed to recover the local temperature field, $T(r, z)$. Assuming that soot particles radiate according to Plank's law for black bodies, the comparison of the signal cap- 
tured over two spectral ranges leads to a unique temperature at each location. Signals from the green and red CCDs are preferentially investigated, since they feature the highest signal-to-noise ratios.

After the experimental validation of the optical setup was carried out over an academic configuration [26], it is embedded in the parabolic flight rig DIAMONDS.

\subsection{Flow conditions}

The present study is restricted to steady flow conditions. For every set of conditions, 50 images featuring the flame with backlight and 50 images featuring the flame without backlight are averaged over a steady spread rate period to enhance the signal-to-noise ratio [26]. Given the frame rate, this means that propagation at steady spread rate will be further processed provided that it persisted longer than $3 \mathrm{~s}$.

To investigate in details flow conditions compatible with human life, the present setup allows for the investigation over a specific range of flow parameters. The pressure, $P$, can be adjusted from 0.5 atm $(50.7 \mathrm{kPa})$ to 1.4 atm $(141.8 \mathrm{kPa})$, and the free stream oxygen molar fraction, $x_{O_{2}, \infty}$, varies from 18 to $21 \%$. The oxidizer flow velocity, $u_{\infty}$, can be tuned between 100 and 200 mm.s ${ }^{-1}$, a range which ideally highlights the specific impact of microgravity on combustion [42] while avoiding unwanted flow distortions induced by the aircraft g-jitters at low flow momentum [43]. All conditions remain within the domain allowing potential flame propagation [14] while soot signal is high enough to enable the B-MAE technique [44].

Two hundred and twenty parabolas were devoted to the investigations of the opposed flame spread over the polyethylene-coated wire in the above range 
of ambient flow conditions. Over these 220 experiments, 142 are considered in the following analysis. Nine were removed due to highly unsteady propagation periods linked to g-jitters, 8 because of poor signal-to-noise ratio on the recorded frames, 21 due to the difficulty to finely anticipate the flame luminosity at unexplored flow conditions which can lead to signal saturation of the red and/or green channels, 18 for having a steady spread propagation for less than 3s, and 22 due to the bubbling at the surface of the molten PE insulation that results in unsteady combustion in the gas phase [45]. The latter perturbation might be a very temporary phenomenon, hence could be readily removed from the recordings to be processed. However, the probability of recording undisrupted flame spread over the minimum period of time required goes down as pressure and/or oxygen content (and consequently bubbling) increase. For this reason, several high-pressure tests were conducted but could not be exploited. Eventually, 7 of the 12 targeted high-pressure cases $(141.8 \mathrm{kPa})$ were successfully captured, with up to 3 repetitions to assess the validity of the measurements. The good agreements between repeated tests sustained confidence in these high-pressure results. Given the low probability of success for the last 5 cases and the limited access to microgravity, the high pressure boundary for the remaining set of data was then lowered. Table 1 lists the final pressure range investigated for the three velocities and four levels of oxygen content of concern.

Ninety-one different ambient flow conditions are spanned over the 142 parabola considered. A wide range of conditions is covered to establish experimental trends with some confidence, while reproducibility is addressed by investi- 


\begin{tabular}{cc|cccc}
\hline & & \multicolumn{4}{|c}{$\mathrm{x}_{O_{2}}(\%)$} \\
& & 18 & 19 & 20 & 21 \\
\hline $\mathrm{u}_{\infty}$ & 100 & $70.9-141.8(11)$ & $60.0-141.8(21)$ & $70.9-121.6(6)$ & $50.7-101.3(4)$ \\
$\left(\mathrm{mm} . \mathrm{s}^{-1}\right)$ & 150 & $70.9-141.8(7)$ & $50.7-141.8(25)$ & $50.7-141.8(11)$ & $50.7-141.8(13)$ \\
& 200 & $70.9-141.8(11)$ & $50.7-130.0(21)$ & $70.9-139.0(7)$ & $50.7-90.4(5)$ \\
\hline
\end{tabular}

Table 1: Range of pressure in $\mathrm{kPa}$ and number of test (into bracket) for each set of flow velocity and oxygen content investigated.

gating some conditions up to 5 times.

\section{Results and discussions}

\subsection{Analysis assumptions}

A scaling analysis is developed to interpret the experimental measurements. Key assumptions are listed as follow:

$\mathbf{A}_{1}$ The flow is assumed to be steady and axisymmetric.

$\mathbf{A}_{2}$ In the context of parabolic flight, the flow is non-buoyant.

$\mathbf{A}_{3}$ A simple one-step reaction, $F+S O_{x} \longrightarrow(1+S) P$, is considered. The oxidizer/fuel mass ratio, $S$, is a decreasing function of the oxygen content $x_{O_{2}, \infty}$. The fuel is assumed to be pure ethylene (discussed at the end of this list), then $S$ and $x_{O_{2}, \infty}$ are related by:

$$
1+S=1+3 \frac{32+28 \frac{1-x_{O_{2}, \infty}}{x_{O_{2}, \infty}}}{28}
$$

Over the range of $x_{O_{2}, \infty}$ investigated, i.e $18-21 \%,(1+\mathrm{S})$ decreases from 19.1 to 15.7. Values are reported in Table 2. 
$\mathbf{A}_{4}$ The combustion is assumed to be complete, i.e. all the fuel is oxidized at the flame tip with $\mathrm{L}_{f l}$ denoting the stoichiometric flame length. This assumption does not hold for the flames investigated in this study that experience quenching at the flame trailing edge. This implies that the stoichiometric flame length is not a relevant length scale to characterize soot production as discussed in Ref. [46, 47]. A more relevant length scale for soot production, denoted $\mathrm{L}_{s}$, can be defined as the distance from the molten insulation droplet leading edge to the peak of $F_{s}$, where $F_{s}(z)=\int_{0}^{\infty}\left(2 \pi r f_{s}(r, z)\right) d r$ is the integrated soot volume fraction at any given streamwise coordinate $z[46,47]$.

$\mathbf{A}_{5}$ The Schmidt number is assumed to be equal to $1\left(S c=\frac{\mu_{f l}}{\rho_{f l} D_{f l}}=1\right)$. Though the momentum diffusivity and the mass one are functions of ambient pressure and local temperature, which vary from one set of flow conditions to the next, this hypothesis is adopted to relate this analysis to existing models of flame spread rate in the configuration studied.

$\mathbf{A}_{6} \Delta h_{c}$ being the ethylene heat of combustion, $c_{p, f l}$ the specific heat capacity of the gas phase, and $\mathrm{T}_{\infty}$ the free stream temperature, the flame temperature can be roughly estimated as $T_{f l} \approx T_{\infty}+\left(\Delta h_{c}\right) /\left[c_{p, f l}(1+S)\right]$ [50], neglecting the radiative loss and cooling effects due to the oxidizer flow. This implies that flame temperature is more sensitive to $x_{O_{2}, \infty}$ than to pressure and oxidizer velocity.

$\mathbf{A}_{7}$ Gas phase thermal properties, namely gas conductivity, $k_{f l}$, and, viscosity, $\mu_{f l}$, vary with flame temperature and pressure as: $k_{f l}=C P^{0} T_{f l}^{1 / 2}$ 
and $\mu_{f l}=C P^{0} T_{f l}^{1 / 2}[51]$.

$\mathbf{A}_{8}$ The soot production rate, $\dot{\omega}_{S P}^{\prime \prime \prime}$, is assumed to scale with $\mathrm{P}^{n_{S}^{P}}$. Previous studies in laminar coflow axisymmetric diffusion flames at normal gravity suggested that $\mathrm{n}_{S}^{P}$ is positive and depends on both fuel and pressure range [32, 52-55]. In addition, the soot production rate is affected by flame temperature and this dependence is assumed to scale as $(1+\mathrm{S})^{n_{S}^{o x}}$. These two assumptions lead to $\dot{\omega}_{S P}^{\prime \prime \prime}=C(1+S)^{n_{S}^{o x}} P^{n_{S}^{P}}$.

$\mathbf{A}_{9}$ The coated wire behaves as a thermally-thin material. This assumption is partly justified based on a previous numerical analysis [28]. In addition, the surface temperature of the fuel is assumed to remain constant during the pyrolysis process and will be denoted as $\mathrm{T}_{F}$ hereafter.

$\mathbf{A}_{10}$ The flame spread occurs within the thermal regime, since moderate stretch rates prevent any quenching or blow-off extinction $[8,50]$.

\begin{tabular}{ccccc}
\hline$x_{\mathrm{O}_{2}}(\%)$ & 18 & 19 & 20 & 21 \\
\hline $1+\mathrm{S}$ & 18.1 & 17.2 & 16.4 & 15.7
\end{tabular}

Table 2: Correspondence between $x_{\mathrm{O}_{2}}$ and $(1+\mathrm{S})$ over the range of conditions investigated.

Assuming that polyethylene is pyrolyzed as ethylene is a rough approximation [56]. Thermal decomposition of plastics actually generates a large variety of hydrocarbons with different molecular weights directly related to the length of the carbon chains, and the relative proportion of each component depends on the thermodynamics of the process. For instance, pyrolysis of polyethylene in nitrogen at $850 \mathrm{~K}$ with a residence time of $600 \mathrm{~ms}$ was shown to yield 
approximately $36 \%$ of ethylene, $25 \%$ of methane, $16 \%$ of propylene, $7 \%$ of butadiene, $6 \%$ of butene, and $2 \%$ of ethane in mass, the last $8 \%$ being a mix of larger polymers and char [57]. The same process at $770 \mathrm{~K}$ approximatively yields $27 \%$ of ethylene, $22 \%$ of methane, $18 \%$ of propylene, $8 \%$ of butadiene, $11 \%$ of butene, and $2 \%$ of ethane in mass. Ethylene is thus the principal component of LDPE pyrolysis, and methane, which comes second, exhibit a poor sooting tendency [58]. Yet, the important sooting tendency of larger polymers, though in limited proportions in the pyrolysis products, impacts the flame morphology [59] as illustrated by smoke point measurements [60]. This being said, numerical simulations of flames established over LDPE in microgravity showed a good correlation with experimental results in terms of temperature fields and stand-off distance when implementing the chemistry of ethylene $[28,61]$. This should be related to the fact that ethylene and polyethylene exhibit a similar stoichiometry and heat of combustion (see Tables 1-5.3, 3-4.10 and 3.2-1 in Ref. [60]).

The subsequent analysis aims to quantify how flame spread and related quantities depend on flow parameters in the studied range. Consequently, experimental measurements concerning oxygen, flow velocity, and pressure effects on flame spread rate, characteristic length scale for soot formation, characteristic residence time for soot production, and maximum soot volume fraction are analysed by using power-law models. Since the power of variation is the variable of interest, least square optimization is carried out for each flow parameter $X=\left((1+S), u_{\infty}, P\right)$ and each flame parameter $Y=\left(u_{p}, L_{s}, f_{s, \max }\right)$ using logarithmic transform.

$$
Y=\alpha X^{\beta} \Longleftrightarrow \log (Y)=\log (\alpha)+\beta \log (X)
$$


Values of $\beta$ are cautiously investigated and reported hereafter.

\subsection{Effects on flame spread rate and pyrolysis mass flow rate}

In the present analysis, recorded flame spread rate ranges from $1.06 \mathrm{~mm} . \mathrm{s}^{-1}$ to $1.71 \mathrm{~mm} . \mathrm{s}^{-1}$.

Based on the assumptions $\mathrm{A}_{2}, \mathrm{~A}_{3}, \mathrm{~A}_{5}, \mathrm{~A}_{9}$, and $\mathrm{A}_{10}$, the spread velocity, $\mathrm{u}_{p}$, is expected to vary as follows [48]:

$$
u_{p}=\frac{\dot{Q}_{f l}+\dot{Q}_{c}}{\left(A_{S F} \rho_{S F} c_{p, S F}+A_{\text {core }} \rho_{\text {core }} c_{p, \text { core }}\right)\left(T_{F}-T_{\infty}\right)}
$$

where $\rho, c_{p}$, and A indicate the density, the specific heat, and the crosssectional area, respectively, and the subscripts indicate the solid fuel and metallic core, respectively. Heat conduction from the flame to the insulation, and heat conduction from the core to the insulation are referred to as $\dot{Q}_{f l}$ and $\dot{Q}_{c o r e}$, respectively. In the present analysis, material properties and dimensions are kept constant. As such, the effect of varying opposed flow conditions on spread rate is primarily felt through $\dot{Q}_{f l}$. This term can be expressed as [8]:

$$
\dot{Q}_{f l}=P_{s} k_{f l}\left(T_{F}-T_{F}\right) \frac{L_{g}}{r_{s} \ln \left(1+L_{g} / r_{s}\right)}
$$

with $P_{s}$ and $r_{s}$ being the perimeter and radius of the sample, respectively, and $L_{g}$ the preheat length. The fraction on the right hand side is a corrective factor introduced by Delichatsios [49] to extend De Ris' theory of flame spread over plate to cylindrical samples [50]. In the case of a thin plate, $\dot{Q}_{f l}$ depends on the oxygen content through the flame temperature, with an indirect dependency through $k_{f l}$ (hypotheses $\mathrm{A}_{6}$, and $\mathrm{A}_{7}$ ), but is independent on the oxidizer velocity and pressure. The corrective term introduces a dependency 
on flame temperature, pressure, and oxidizer velocity through variations in the preheat length in the gas phase, defined as $L_{g}=k_{f l} /\left[\rho_{f l} c_{p, f l}\left(u_{\infty}+u_{p}\right)\right]$. As such, it is expected that the spread rate increases rapidly with oxygen content, and slightly decreases with both pressure and flow velocity through the corrective factor.

\subsubsection{Effects of oxygen content, flow velocity, and pressure}

Figure 2 shows the impact of the oxygen content on the flame spread rate. The leftmost plot reports all experimental data points, together with error bars for repeated conditions, while the plot on the right shows the slopes of the power-law models (see Eq.(2)) obtained for a given pressure and flow velocity. This representation is repeated throughout the present paper.

Thirteen sets of $\left(u_{\infty}, \mathrm{P}\right)$ featuring at least two oxygen content levels, hence two or more values of $(1+\mathrm{S})$, are investigated. These 13 sets lead to an av-

erage value $\beta_{u_{p}}^{1+S}=-1.06$ with a standard deviation of 0.73 . This negative exponent implies that, as expected, the spread rate increases with the oxygen content. The standard deviation is relatively high. This can be attributed to the difficulty to get a stable flame at higher pressure, higher oxygen content, and lower flow rate. In such situation, numerous bubbles of gas are visualized in the molten insulation droplet, as already reported in similar microgravity configurations [14]. Since the boiling temperatures of some PE degradation products are much lower than the full degradation temperature of PE [57], when the degradation products are formed inside the sample they are immediately superheated and form bubbles [7] which grow by accumulation of degradation products through diffusion in the molten polyethylene. As they become sufficiently large and close to the surface, a sudden rupture of the 
liquid interface creates a liquid jet, ejecting fragments of the molten PE into the gas phase. These beads of dense fuel create unsteady fluctuations in the flame luminosity and shape. Removing a set of data points corresponding to (141.8 $\mathrm{kPa}, 100 \mathrm{~mm} . \mathrm{s}^{-1}$ ) conditions, the 12 sets left lead to an average value $\beta^{\prime 1+S}=-1.18$, and the standard deviation drops to 0.62 .

Figure 3 details the data relative to the influence of flow velocity on flame spread rate. The analysis of the experimental data for the 33 sets of $(P$, $(1+\mathrm{S}))$ conditions investigated at more than two flow velocities shows that $u_{f l}=C u_{\infty}^{\beta_{u_{p}}^{u_{\infty}}}$ with $\beta_{u_{p}}^{u_{\infty}}=-0.12 \pm 0.13$. This corroborates the idea that flow velocity does not influence flame spread rate within the range of conditions investigated. Such an observation sustains assumption $\mathrm{A}_{10}$ that the present flame spreads in the thermal regime [8]. Pressure also has little to no influence over the level of flame spread rate. Averaged results over the 12 sets of $\left((1+\mathrm{S}), u_{\infty}\right)$ conditions investigated at two or more pressure levels lead to $u_{p}=C P^{\beta_{u_{p}}^{P}}$ with $\beta_{u_{p}}^{P}=-0.09 \pm 0.14$. Data points are illustrated on Fig. 4, organised under the same structure as before.

The marginal effect of both pressure and flow velocity on spread rate reported here is the consequence of two different causes. First, the range of conditions studied, though broad enough to show large changes in soot properties as displayed in Fig. 1, is too narrow to capture variations of spread rate. Second, heat conduction through the core dampens the effect of variations of $\dot{Q}_{f l}$ on the spread rate. Although these two considerations would be an issue within the context of a spread rate analysis, they provide a range of conditions where the spread rate variation, of the same order as the measured uncertainty, can be assumed to be constant. This supports the need 
for further investigation on the cause of the dramatic increase in soot volume fraction reported in Fig. 1.

\subsubsection{Impact on pyrolysis mass flow rate}

The pyrolysis mass flow rate, $\dot{m}_{F}$, is determined from the flame spread rate using the following relationship [27]:

$$
\dot{m}_{F}=\rho_{S F} u_{p} \pi\left(r_{\text {wire }}^{2}-r_{\text {core }}^{2}\right)
$$

Therefore, the pyrolysis mass flow rate is expected to follow the same trends as the flame spread rate, i.e. increasing with $x_{O_{2}, \infty}$ and being marginally affected by variations in flow velocity or pressure. It should be stressed again that all the results obtained hereafter should not be extrapolated to a broader range of flow conditions, since large pressure and oxidizer flow variations are expected to modify the spread rate. Within the context of space exploration however, there is a limited benefit in investigating pressure and flow velocities out of the present range.

\subsection{Characteristic length scale for soot production}

Figure 5 shows the configuration studied and the characteristic parameters used in the subsequent scaling analysis. Based on assumption $A_{1}$, the mass conservation at the flame tip can be expressed as:

$$
(1+S) \dot{m}_{F}=C \rho_{f l} u_{f l} \delta_{f l}^{2}
$$

with $\mathrm{u}_{f l}=\mathrm{u}_{\infty}+u_{p}$. The flame width can be related to the flame length by considering the conservation of fuel mass fraction and equating the time 
scale for convection along the wire to the time scale for fuel diffusion in the radial direction:

$$
\frac{u_{f l}}{L_{f l}}=C \frac{D_{f l}}{\delta_{f l}^{2}}=C \frac{\nu_{f l}}{\delta_{f l}^{2}}
$$

It should be pointed out that $\mathrm{A}_{5}$ has been introduced to get the final expression in Eq.(7). Then introducing Eq.(6), an expression for $L_{f l}$ can be obtained:

$$
L_{f l}=C \frac{(1+S) \dot{m}_{F}}{\mu_{f l}}=C u_{\infty}^{0} P^{0}(1+S)^{m}
$$

Equation (8) shows that $\mathrm{L}_{f l}$ is independent on pressure and flow velocity. A value of $\mathrm{m}$ can be roughly estimated from Section 4.2.2 and assumptions $\mathrm{A}_{5}$ and $\mathrm{A}_{6}$ as $m=1.5+\beta_{u_{p}}^{1+S} \approx 0.5$. As a consequence, the analysis predicts that the stoichiometric flame length decreases as $x_{O_{2}, \infty}$ increases.

The stoichiometric flame length is not a relevant quantity to define a flow residence time for soot production in such diffusion flames that experience flame quenching at the trailing edge. With soot measurements at the centre of the present paper, a more relevant definition of a length, $\mathrm{L}_{s}$, based on soot properties is consequently adopted, as stated in $\mathrm{A}_{4}$. It is defined as the distance between the pyrolysis front and the position of the peak of integrated soot volume fraction along the wire axis. The pyrolysis front corresponds approximately to the position where polycyclic aromatic hydrocarbons (PAH) start to be formed [62], whereas the peak integrated soot volume fraction marks the location where soot oxidation balances soot formation [63-65]. Consequently, $\mathrm{L}_{s}$ corresponds to the characteristic distance over which soot particles can be produced and grow. Experimentally, the pyrolysis front location is defined as the leading edge of the molten insulation droplet. Fuel is thus assumed to vaporise as soon as the liquid phase appears, which is 
supported by the fact that LDPE melts at $390 \mathrm{~K}$ [66] while pyrolysis is initiated at $400 \mathrm{~K}$ [56]. In the meantime, the position of the peak integrated soot volume fraction is computed from fields of soot volume fraction yielded by the B-MAE technique. In the present analysis, $\mathrm{L}_{s}$ ranges from $9.69 \mathrm{~mm}$ to $13.96 \mathrm{~mm}$.

\subsubsection{Effects of oxygen content, flow velocity, and pressure on $L_{s}$}

The data reported in Figs. 6, 7, and 8 lead to $\beta_{L_{s}}^{1+S}$, $\beta_{L_{s}}^{u_{\infty}}$, and $\beta_{L_{s}}^{P}$ equal to $-1.19,-0.08$, and -0.08 with standard deviations of $0.75,0.14$, and 0.06 , respectively. These results show that $\mathrm{L}_{s}$ is independent of pressure and flow velocity. On the other hand, the experimental data show that $\mathrm{L}_{s}$ increases with oxygen content, which is opposed to the effect of oxygen content on $\mathrm{L}_{f l}$ according to the model expressed by Eq.(8). This confirms that the flame length cannot be used as a characteristic length scale for soot production processes as discussed in $\mathrm{A}_{4}$.

\subsubsection{Impact on soot production residence time}

The characteristic flow time scale for the soot production process can be estimated as follows:

$$
t_{r e s, s}=C \frac{L_{s}}{u_{\infty}}=C u_{\infty}^{-1} P^{0}(1+S)^{\beta_{L_{s}}^{1+S}}=C u_{\infty}^{-1} P^{0}(1+S)^{-1.19}
$$

Equation (9) shows that the flow residence time for soot production decreases as the flow velocity increases, also increases with $x_{O_{2}, \infty}$, and is independent on pressure. This latter conclusion has to be combined with the results of Section 4.2, which show that pyrolysis mass flow rate is also independent on pressure. Fuel injection rate has been identified as a key factor of soot 
formation in laminar diffusion flames [67]. For given $x_{O_{2}, \infty}$ and $u_{\infty}$, soot production processes consequently experience the same residence time and pyrolysis mass flow rate whatever the pressure under consideration. It is then relevant to compare the effects of pressure on soot volume fraction profiles at given distance from the molten insulation droplet leading edge (as initially done in Fig.1), which will highlight consequence of ambient flow and not fuel flow rate conditions.

\subsection{Soot production}

Maximum soot volume fraction varies significantly with ambient conditions, ranging from $1 \mathrm{ppm}$ to $55 \mathrm{ppm}$ in the present study. The conservation of soot volume fraction can be written in a Lagrangian sense as:

$$
\frac{D\left(\rho_{s} f_{s}\right)}{D t}=\frac{D\left(\rho Y_{s}\right)}{D t}=\dot{\omega}_{S P}^{\prime \prime \prime}
$$

and then be re-expressed as:

$$
\frac{D\left(\rho_{s} f_{s}\right)}{D t}=C \frac{\rho_{s} f_{s, \max }}{t_{r e s, s}}=\dot{\omega}_{S P}^{\prime \prime \prime}
$$

Using Eq.(11) and $A_{8}$, an expression for the maximum soot volume fraction can be obtained:

$$
f_{s, \max }=C t_{r e s, s} \dot{\omega}_{S P}^{\prime \prime \prime}=C u_{\infty}^{-1} P^{n_{S}^{P}}(1+S)^{\beta_{L_{s}}^{1+S}+n_{S}^{o x}}
$$

with $\beta_{L_{s}}^{1+S}=-1.19$.

\subsubsection{Pressure and oxygen content effects}

An important feature of the independence of soot production residence time on pressure is that the measure of the peak soot volume fraction allows 
determining the soot production reaction order in pressure. Figure 9 shows that the soot production rate in the present flames is approximately thirdorder in pressure, with $n_{s}^{P}=\beta_{f_{s, \max }}^{P}=2.96$. The standard deviation is only of 0.29 , hence $\pm 9.7 \%$, supporting the robustness of this conclusion. It should be pointed out that the present value of $n_{s}^{P}$ is not expected to be universal. As discussed previously, recent experimental studies suggest that this value depends on the fuel and on the pressure range at normal gravity [32, 52-55]. The oxygen content affects $f_{s, \max }$ through its effects on both soot production residence time and soot production rates. Figure 10 shows that $f_{s, \max }$ scales as $(1+S)^{\beta_{f_{s, \max }}^{1+S}}$ with $\beta_{f_{s, \max }}^{1+S}=n_{S}^{o x}+\beta_{L_{S}}^{1+S}=-8.06$. The standard deviation is reported as 3.79 , which means a $\pm 47 \%$ deviation. This high value of the standard deviation can be partially explained by two data sets, namely $\left(\mathrm{P}=50 \mathrm{kPa}, \mathrm{u}_{\infty}=200 \mathrm{~mm} \cdot \mathrm{s}^{-1}\right)$ and $\left(\mathrm{P}=100 \mathrm{kPa}, \mathrm{u}_{\infty}=150 \mathrm{~mm} . \mathrm{s}^{-1}\right)$, which evolve in a contradictory trend as compared to the other data. If these two data sets are suppressed the value of $\beta_{f_{s, \text { max }}}^{1+S}$ becomes -9.3 and the standard deviation drops to \pm 1.95 which amounts to $21 \%$. As a consequence, $n_{S}^{o x} \approx-10.49$. The negative value of $n_{S}^{o x}$ shows that, as expected, soot production rate is enhanced by increasing the oxygen content. In addition, it appears clearly that soot production is more sensitive to oxygen content than to pressure.

\subsubsection{Flow velocity effects}

Equation (12) predicts that $f_{s, \max }$ decreases when increasing the flow velocity owing to a reduction in flow residence time. Nevertheless, an opposite trend is observed in Fig. 11 which highlights that $f_{s, \max }$ scales as $u_{\infty}^{\beta_{f_{s, \text { max }}}^{u}}$ with $\beta_{f_{s, \text { max }}}^{u_{\infty}}=0.66$, and a deviation of 0.40 hence $\pm 60 \%$. 
The flow velocity may affect the soot production through two competitive processes. On the one hand, a reduction in flow velocity increases the flow residence time which favours the soot production whereas, on the other hand, this enhancement in flow residence time increases the radiative loss, leading to lower temperature and then tends to inhibit soot formation. As a consequence, the discrepancies between the theoretical analysis, which neglects radiative loss, and the experimental approach support the fact that the second mechanism prevails in the present flames.

The competition between the aforementioned two mechanisms is investigated more deeply using a numerical model describing the gas phase phenomena, including soot production processes in opposed flow flame spread along coated electrical wire [28]. This model was found to properly reproduce the flame structure in terms of soot volume fraction, soot temperature, and stand-off distance. This numerical model is briefly described in Appendix A. Two simulations have been performed by considering an oxygen content of $20 \%$, a pressure of $100 \mathrm{kPa}$ and flow velocities of 100 and $200 \mathrm{~mm} \cdot \mathrm{s}^{-1}$. Based on the experimental evidences discussed previously, the pyrolysis mass flow rate has been maintained constant in both simulations. Other computational details are given in Appendix B.

Figure 12 shows radial profiles of temperature, soot formation rate, defined as the sum of nucleation and surface growth, and soot volume fraction at different locations along the wire. For both flow velocities, the soot volume fraction increases up to $\mathrm{z}=10 \mathrm{~mm}$ before starting to decrease. This delimits the soot growth dominated region and the soot oxidation dominated one. Figure 12 shows clearly that reducing the flow velocity from $200 \mathrm{~mm} \cdot \mathrm{s}^{-1}$ to 
$100 \mathrm{~mm} . \mathrm{s}^{-1}$ leads to a wider flame and tends, as discussed previously, to reduce the temperature in the region of soot formation. This reduction becomes more and more significant as the distance along the wire increases. This has a direct impact on the soot formation rate that is reduced for the lowest flow velocity. Figure 12 also evidences that this reduction in soot formation rate balances the increase in soot formation residence time, resulting in a lower peak of soot volume fraction at $\mathrm{z}=10 \mathrm{~mm}$. These numerical results finally support the finding that velocity affects soot production via the two competitive mechanisms discussed above.

\section{Conclusions}

Soot volume fraction in a flame spreading in an opposed-flow configuration in microgravity is largely affected by ambient conditions. If such conclusions were qualitatively established in past research work, the present analysis provides the relevant quantified experimental data and analysis to understand the mechanisms driving these observations. Spread rate increases with oxygen content, which enhances soot inception rate of the flame. How-

ever, it is marginally affected by both flow rate and pressure in the present experimental ranges relevant to space environments. These two parameters also have little impact on the characteristic length scale for soot formation, defined as the distance between the fuel pyrolysis front and the location of maximum integrated soot volume fraction. Consequently, soot formation residence time is independent of pressure, and maximum soot volume fraction variations with pressure suggest a cubic dependency of soot formation rate with pressure. As for flow rate, reduced radiative losses overcome the effect 
of lower residence time at higher flow rate and maximum soot volume fraction increases with flow velocity, as supported by a numerical model. This finding is a major peculiarity of the non-buoyant flames investigated.

A limitation of the present results is the impossibility to compare with data at normal gravity, due to the irregular dripping of molten PE insulation recorded at normal gravity in the same configuration [27]. This dripping varies with flow conditions, and thus adds an additional complexity to the present problem.

Yet, present conclusions will serve as the basis for upcoming quenching and radiative heat feedback analysis, which will support atmospheric choices to limit the threat posed by an accidental fire in terms of flame propagation and smoke emission. Since diffusion flame experiments conducted aboard space stations, with longer observation time available, have reported subsequent discrepancies with Earth-bound facilities such as parabolic aircraft [24], the present results will benefit from the future observations to be conducted soon aboard the International Space Station [68].

\section{Acknowledgements}

The authors feel grateful to the Centre National d'Etudes Spatiales (CNES) for its financial support under Contract No. 130615. 

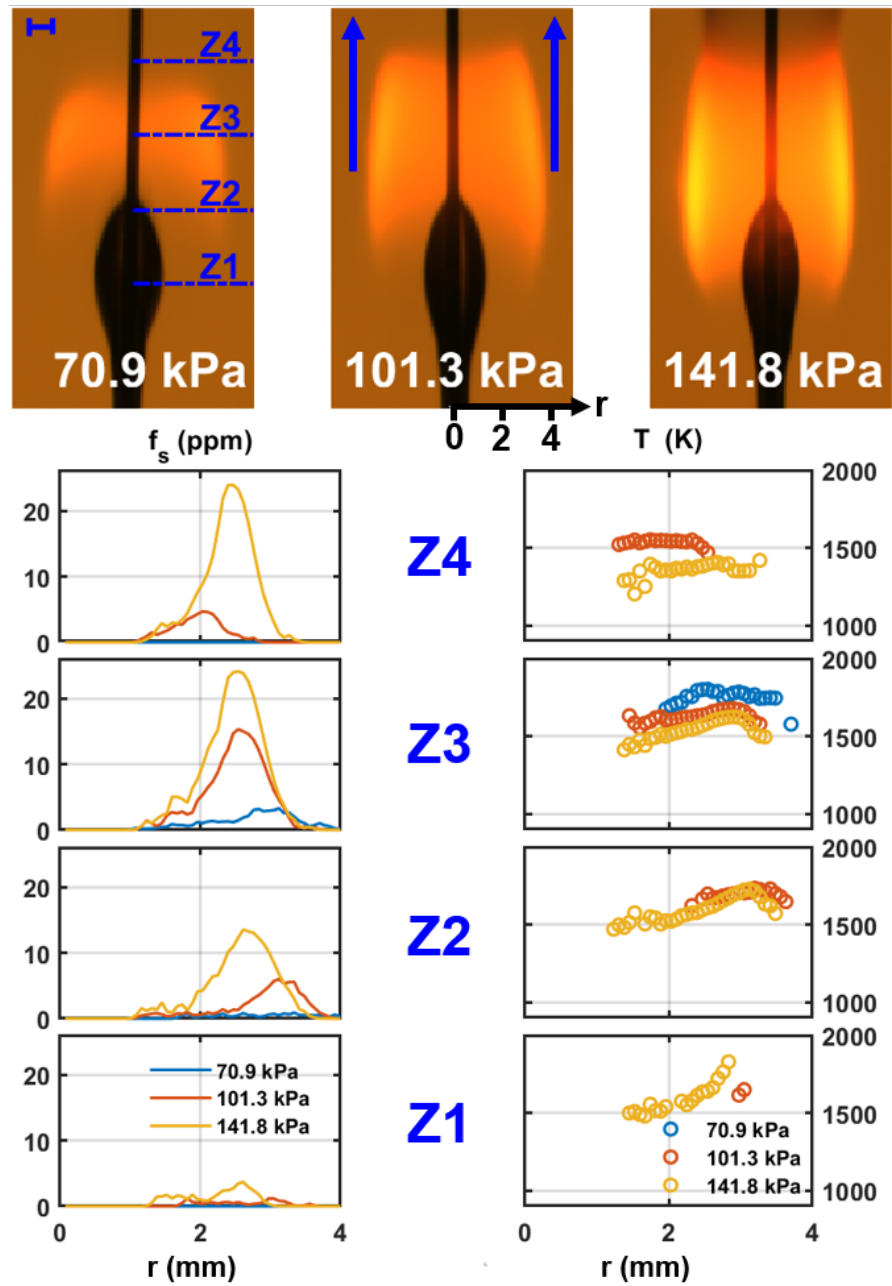

Z3
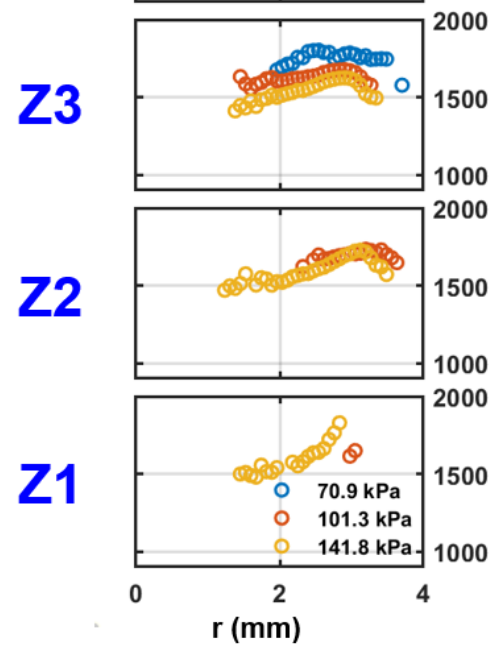

Figure 1: The frames on the top image the impact of pressure on the flame morphology. Opposed flow velocity is $150 \mathrm{~mm} . \mathrm{s}^{-1}$, and oxygen content is $19 \%$ in volume, pressure is set to either $70.9 \mathrm{kPa}$ (left), $101.3 \mathrm{kPa}$ (center) or $141.8 \mathrm{kPa}$ (right). The oxidizer flow direction (center) and a $1 \mathrm{~mm}$ scale (left) are displayed in blue. The backlight is shown on the frames, and captures the molten insulation droplet contour. Radial profiles of soot temperature and volume fraction are displayed on the bottom for four different locations along the wire axis (from Z1 to Z4). Temperature is shown only over locations where the soot volume fraction level exceeds $1 \mathrm{ppm}$ to obtain a satisfactory signal to noise ratio. 

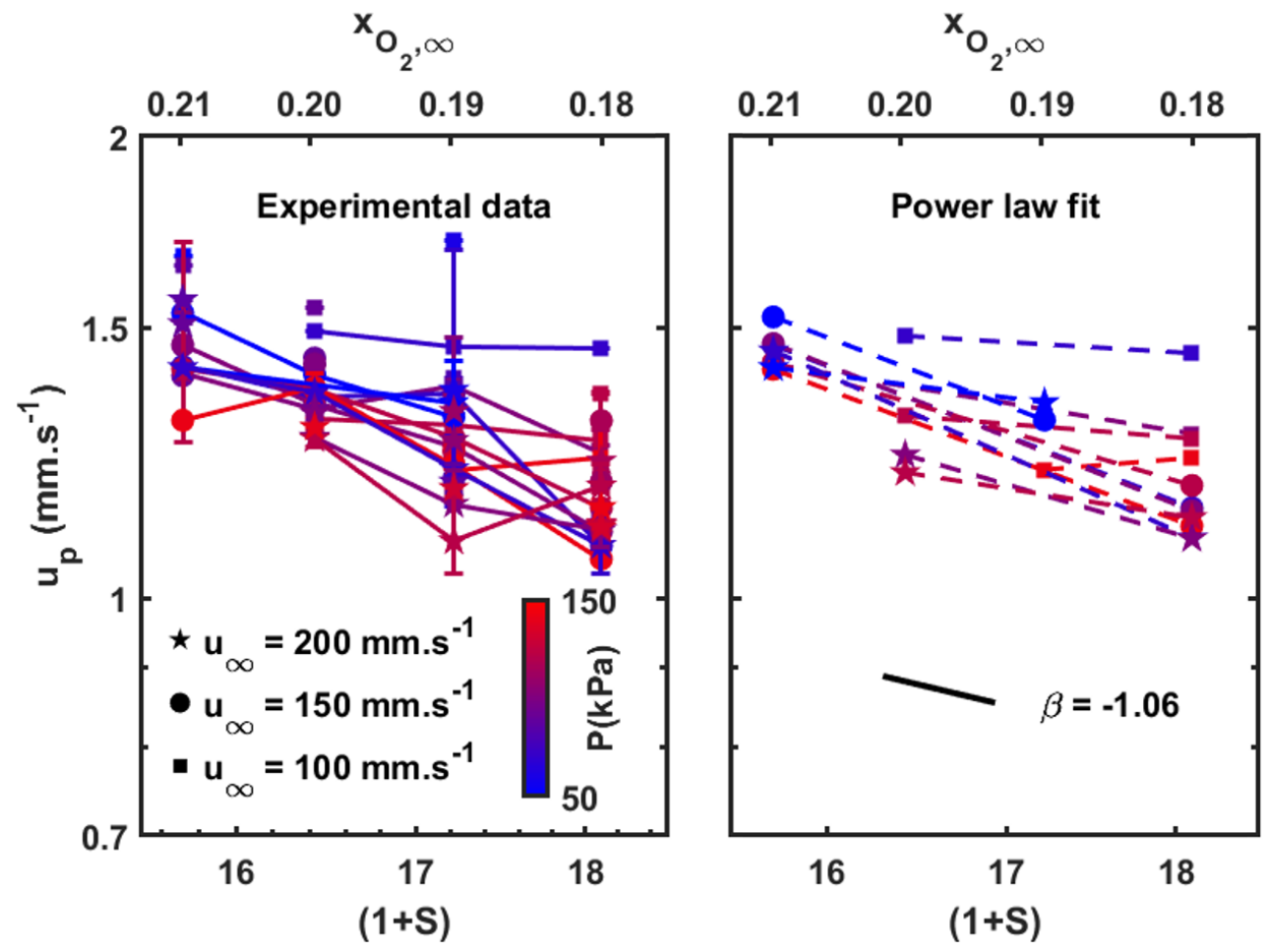

Figure 2: Flame spread rate as a function of $(1+\mathrm{S})$. Experimental data are provided on the left, together with error bars for repeated conditions. The symbols represent the flow velocity conditions, while the color indicates the pressure level. Averaged over 13 sets of given $\left(\mathrm{u}_{\infty}, \mathrm{P}\right)$, each including at least two oxygen content levels, the fitted power law exponent is -1.06 , as illustrated by the dark line, with a standard deviation of 0.73 . 

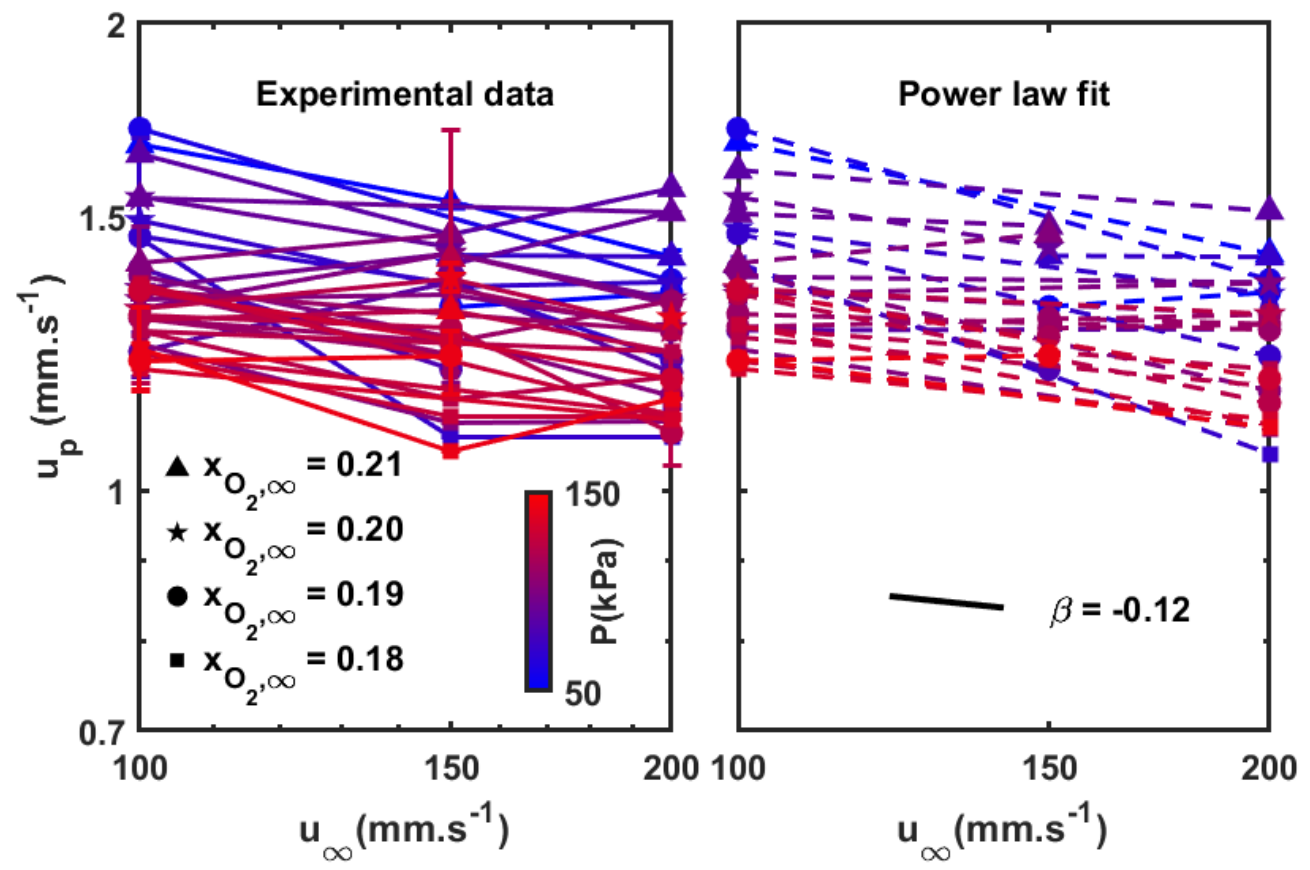

Figure 3: Flame spread rate as a function of flow velocity. The symbols represent the oxygen content, while the color indicates the pressure level. Averaged over 33 sets of given $((1+\mathrm{S}), \mathrm{P})$, the fitted power law exponent is -0.12 , with a standard deviation of 0.13 . 

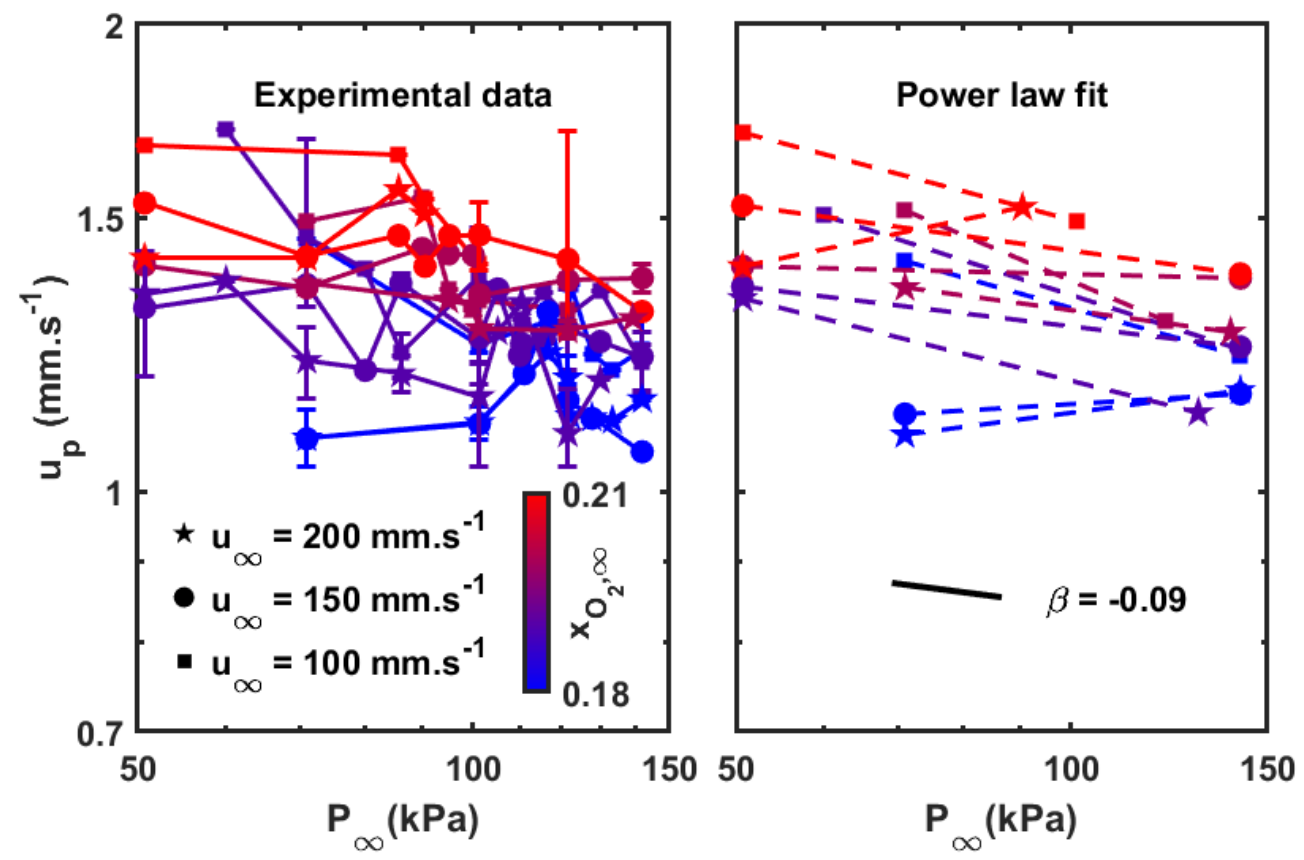

Figure 4: Flame spread rate as a function of ambient pressure. The symbols represent the flow velocity conditions, while the color indicates the oxygen content. Averaged over 12 sets of given $\left(\mathrm{u}_{\infty},(1+\mathrm{S})\right)$, the fitted power law exponent is -0.09 , with a standard deviation of 0.14 . 


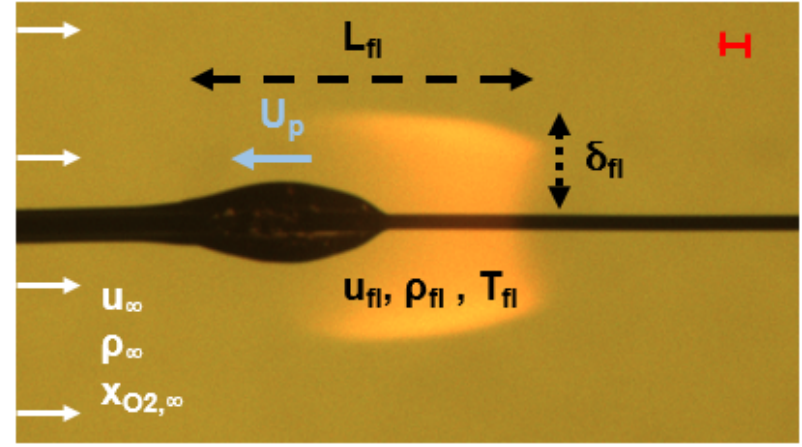

Figure 5: Main features of the flame geometry and subsequent notations adopted, over a backlighted frame imaging a flame spreading in opposed flow conditions in microgravity. A $1 \mathrm{~mm}$ scale is displayed in the upper right corner.
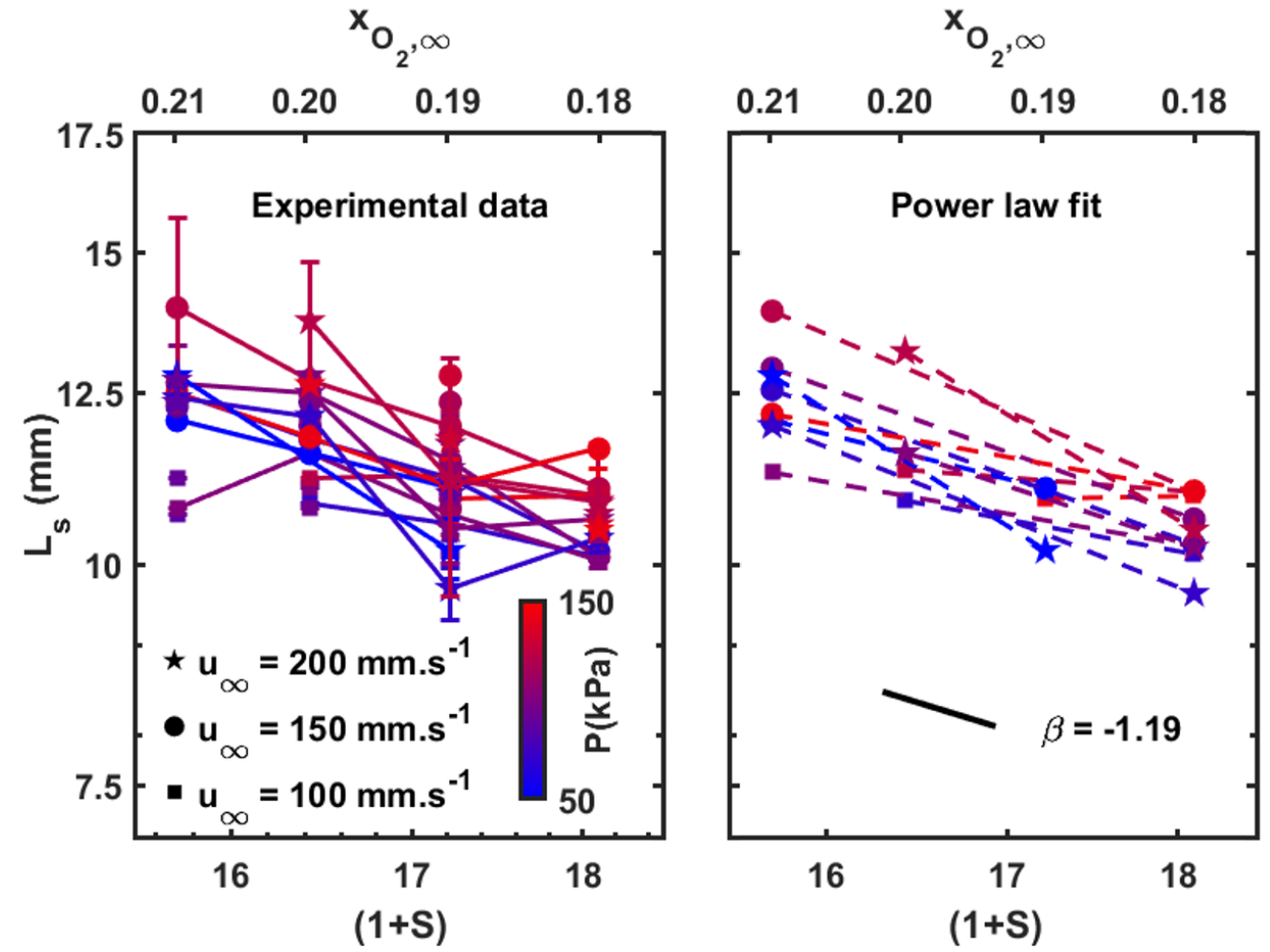

Figure 6: $\mathrm{L}_{s}$ as a function of $(1+\mathrm{S})$. The symbols represent the flow velocity conditions, while the color indicates the pressure level. Averaged over 13 sets of given $\left(\mathrm{u}_{\infty}, \mathrm{P}\right)$, the fitted power law exponent is -1.19 , with a standard deviation of 0.75 . 


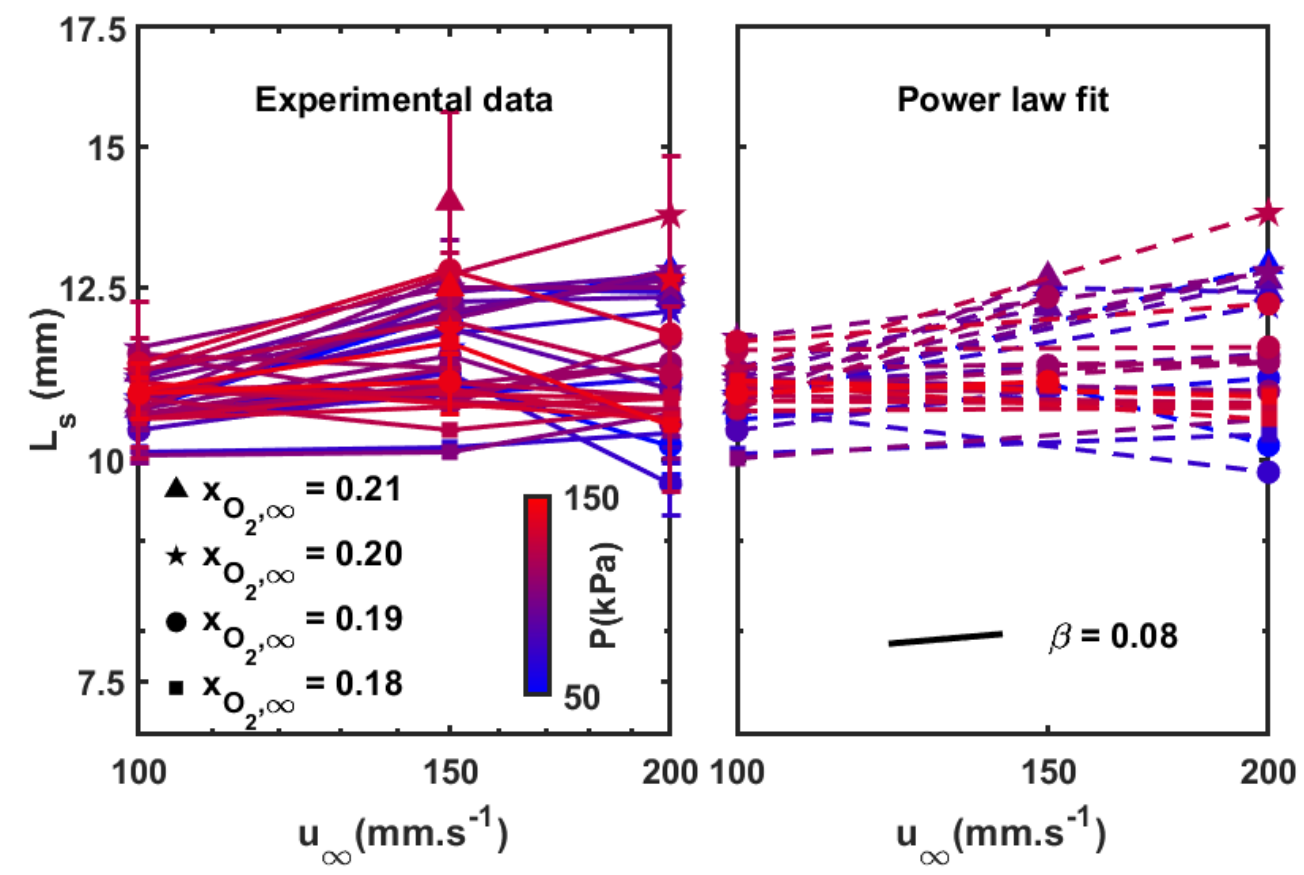

Figure 7: $\mathrm{L}_{s}$ as a function of flow velocity. The symbols represent the oxygen content, while the color indicates the pressure level. Averaged over 33 sets of given $((1+\mathrm{S}), \mathrm{P})$, the fitted power law exponent is 0.08 , with a standard deviation of 0.14 . 

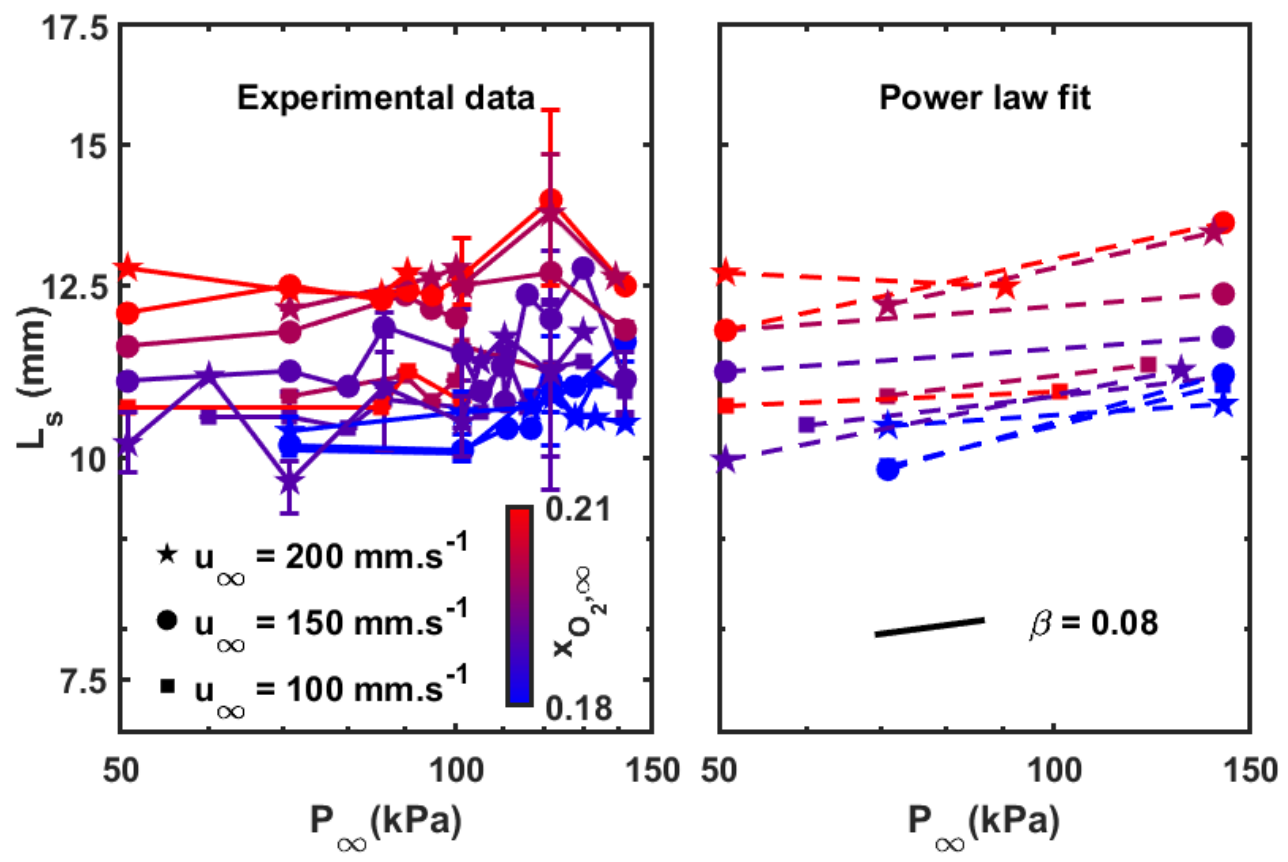

Figure 8: $\mathrm{L}_{s}$ as a function of ambient pressure. The symbols represent the flow velocity conditions, while the color indicates the oxygen content level. Averaged over 12 sets of given $\left(\mathrm{u}_{\infty},(1+\mathrm{S})\right)$, the fitted power law exponent is 0.08 , with a standard deviation of 0.06 . 

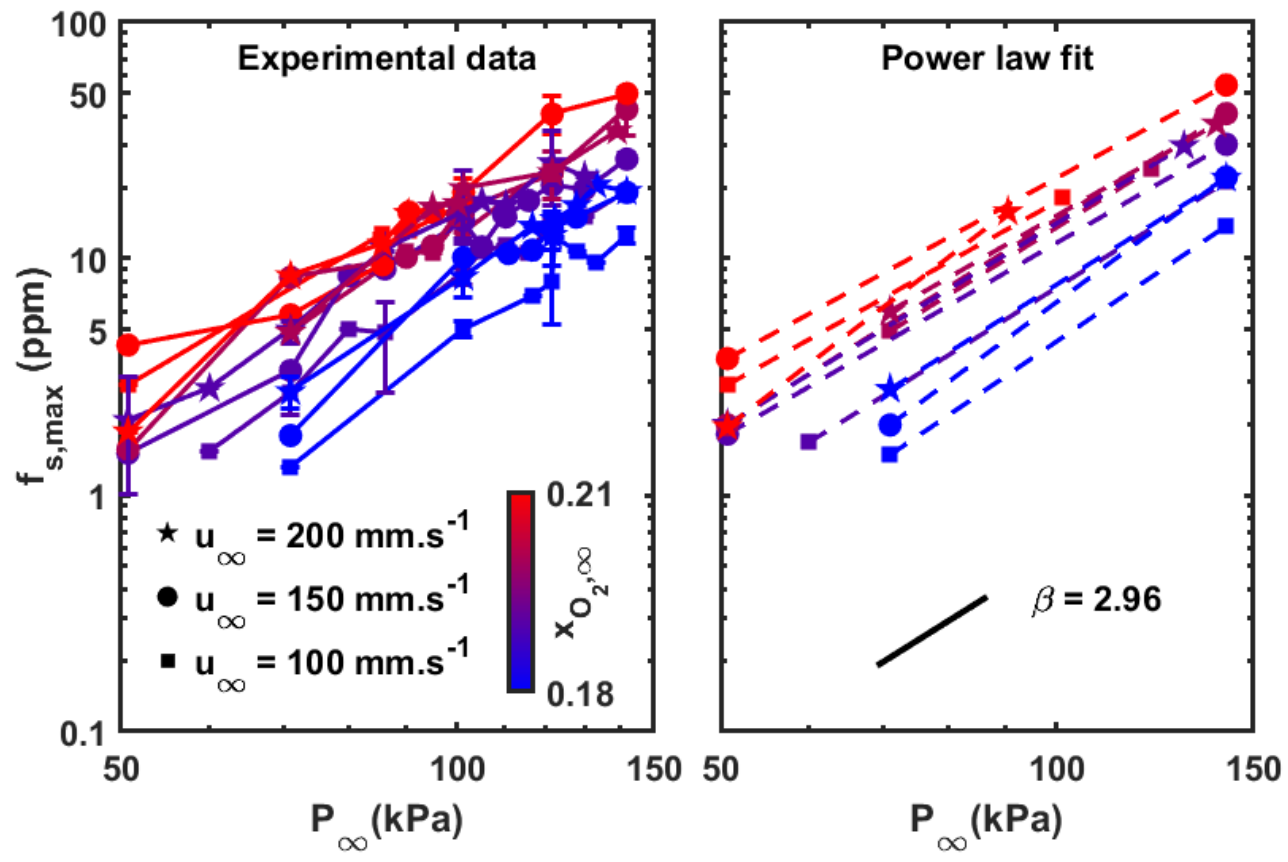

Figure 9: Maximum soot volume fraction as a function of ambient pressure. The symbols represent the flow rate conditions, while the color indicates the oxygen content level. Averaged over 12 sets of given $\left(\mathrm{u}_{\infty},(1+\mathrm{S})\right)$, the fitted power law exponent is 2.96 , with a standard deviation of 0.29 . 

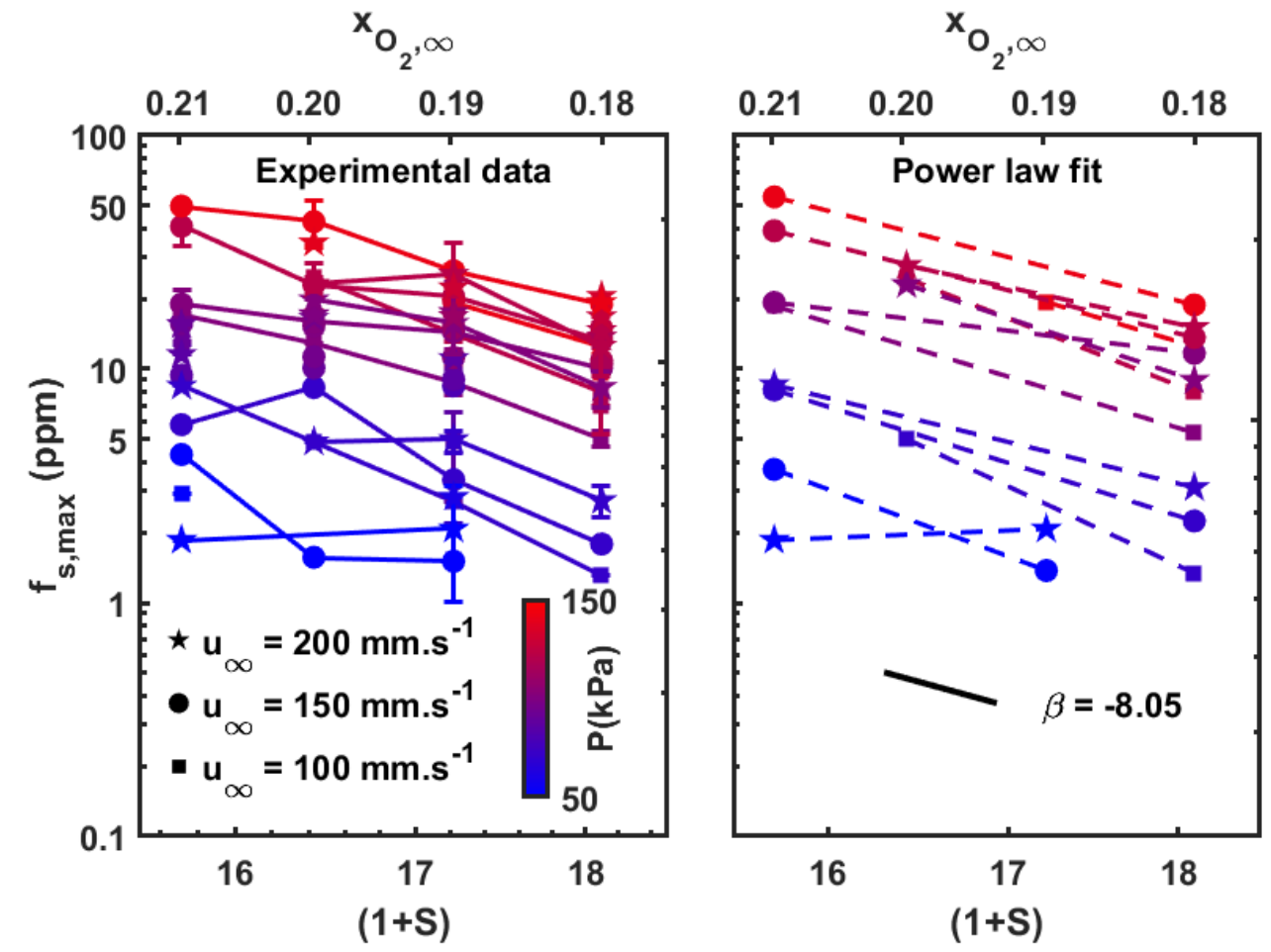

Figure 10: Maximum soot volume fraction as a function of $(1+\mathrm{S})$. The symbols represent the flow rate conditions, while the color indicates the pressure level. Averaged over 13 sets of given $\left(\mathrm{u}_{\infty}, \mathrm{P}\right)$, the fitted power law exponent is -8.05 , with a standard deviation of 3.78. 

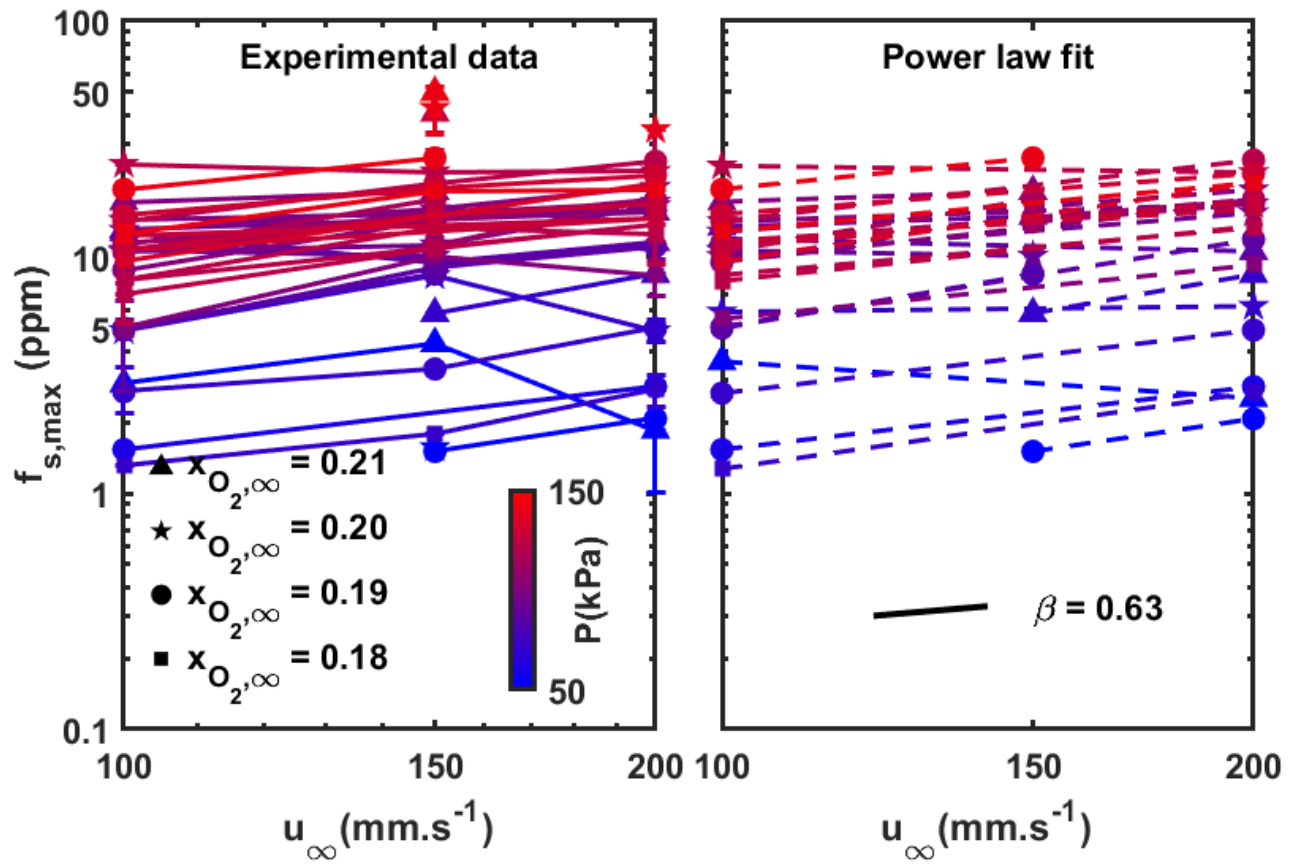

Figure 11: Maximum soot volume fraction as a function of flow velocity. The symbols represent the oxygen content conditions, while the color indicates the pressure level. Averaged over 33 sets of given $((1+\mathrm{S}), \mathrm{P})$, the fitted power law exponent is 0.63 , with a standard deviation of 0.45 . 

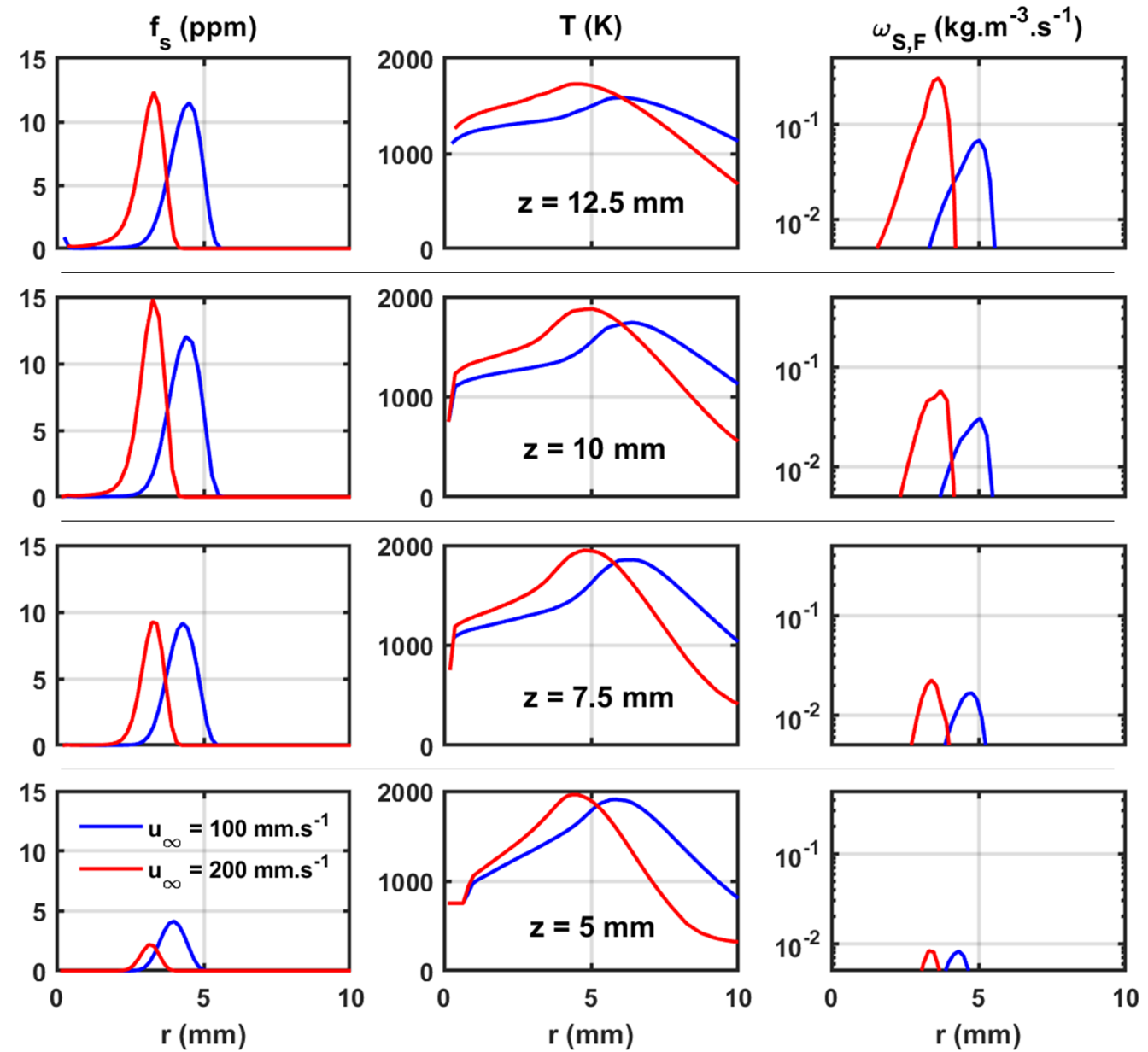

Figure 12: Radial profiles at four different streamwise coordinates $z$ of soot volume fraction (left), temperature (center), and formation rate (right). The profiles are extracted from the numerical simulations of the configuration for two different levels of flow velocity: 100 $\mathrm{mm} . \mathrm{s}^{-1}$ (blue), and $200 \mathrm{~mm} . \mathrm{s}^{-1}$ (red). 
[1] J. Lovell, J. Kluger, Apollo 13, Houghton Mifflin Harcourt (2006).

[2] J.E. Oberg, Star-crossed orbits: inside the US-Russian space alliance, McGraw-Hill Companies (2002).

[3] G.S. Ivanovich, Salyut - the first space station: triumph and tragedy, Springer Science and Business Media (2008).

[4] R. Friedman, Risks and issues in fire safety on the space station, NASA Technical Reports 19940022933 (1994).

[5] J. Graf, C. Dunlap, J. Haas, M. Weislogel, J. Lewis, K. Meyers, A. McKernan, Development of a solid chlorate backup oxygen delivery system for the international space station, SAE Technical Paper No. 2000-01$2348(2000)$.

[6] C. Harrison, S. Weaver, C. Bertelsen, E. Burgett, N. Hertel, E. Grulke, Polyethylene/boron nitride composites for space radiation shielding, J. App. Polymer Sci., 109 (2008), 2529-2538.

[7] P.S. Greenberg, K.R. Sacksteder, T. Kashiwagi, Wire insulation flammability experiment: USML-1 one year post mission summary, NASA Shuttle Mission Summary (1994).

[8] O. Fujita, K. Nishizawa, K. Ito, Effect of low external flow on flame spread over polyethylene-insulated wire in microgravity, Proc. Combust. Inst. 29 (2002), 2545-2552.

[9] Y. Onishi, O. Fujita, K. Agata, H. Takeuchi, Y. Nakamura, H. Ito, M. Kikuchi, Observation of flame spreading over electric wire under 
reduced gravity condition given by parabolic flight and drop tower experiments, Trans. Jap. soc. Aero. Space Sc., Aero. Tech. Jap. 8 (2010), 19-24.

[10] J.M. Citerne, H. Dutilleul, K. Kizawa, M. Nagachi, O. Fujita, M. Kikuchi, G. Jomaas, S. Rouvreau, J.L. Torero, G. Legros, Fire safety in space - investigating flame spread interaction over wires, Acta Astronautica 126 (2016), 500-509.

[11] M. Nagachi, F. Mitsui, J. -M. Citerne, H. Dutilleul, A. Guibaud, G. Jomaas, G. Legros, N. Hashimoto, O. Fujita, Can a spreading flame over electric wire insulation in concurrent flow achieve steady propagation in microgravity?, Proc. Combust. Inst. 37 (2019), 4155-4162.

[12] D.L. Urban, P. Ferkul, S. Olson, G.A. Ruff, J. Easton, J.S. T'ien, Y.T.T. Liao, C. Li, C. Fernandez-Pello, J.L. Torero, G. Legros, C. Eigenbrod, N. Smirnov, O. Fujita, S. Rouvreau, B. Toth, G. Jomaas, Flame spread: effects of microgravity and scale, Combust. Flame 199 (2019), 168-182.

[13] O. Fujita, Solid combustion research in microgravity as a basis of fire safety in space, Proc. Combust. Inst. 35 (2015), 2487-2502.

[14] S. Takahashi, H. Ito, Y. Nakamura, O. Fujita, Extinction limits of spreading flames over wires in microgravity, Combust. Flame 160 (2013), 1900-1902.

[15] J. T'ien, Diffusion flame extinction at small stretch rates: the mechanism of radiative loss, Combust. Flame 65 (1986), 31-34. 
[16] S.L. Olson, P.V. Ferkul, J. T'ien, Near-limit flame spread over a thin solid fuel in microgravity, Symp. Int. Combust. 22 (1989), 1213-1222.

[17] A.F. Osorio, K. Mizutani, C. Fernandez-Pello, O. Fujita, Microgravity flammability limits of etfe insulated wires exposed to external radiation, Proc. Combust. Inst. 35 (2015), 2683-2689.

[18] A.V. Ivanov, Y.V. Balashov, T.V. Andreeva, A.S. Melikhov, Experimental verification of material flammability in space, NASA Technical Reports 20000024924 (1999).

[19] D.J. Barillo, R. Goode, Fire fatality study: demographics of fire victims, Burns 22 (1996), 85-88.

[20] J.B. Haggard Jr, Forced and natural convection in laminar-jet diffusion flames, NASA Technical Paper 1841 (1981).

[21] M.Y. Bahadori, R.B. Edelman, R.G. Sotos, D.P. Stocker, Radiation from gas-jet diffusion flames in microgravity environments, AIAA Journal (1991), 7-10.

[22] P.B. Sunderland, S. Mortazavi, G.M. Faeth, D.L. Urban, Laminar smoke points of nonbuoyant jet diffusion flames, Combust. Flame 96 (1994), 97-103.

[23] M. Kikuchi, O. Fujita, K. Ito, A. Sato, T. Sakuraya, Experimental study on flame spread over wire insulation in microgravity, Int. Symp. Combust. 27 (1998), 2507-2514. 
[24] D.L. Urban, Z.G. Yuan, P.B. Sunderland, G.T. Linteris, J.E. Voss, K.C. Lin, Z. Dai, K. Sun, G.M. Faeth, Structure and soot properties of nonbuoyant ethylene/air laminar jet diffusion flames, AIAA journal 36 (1998), 1346-1360.

[25] G. Legros, A. Fuentes, J. Baillargeat, P. Joulain, J.-P. Vantelon, J.L. Torero, Three-dimensional recomposition of the absorption field inside a non-buoyant sooting diffusion flame, Optics Lett. 30 (2005), 3311-3313.

[26] A. Guibaud, J.M. Citerne, J.M. Orlac'h, O. Fujita, J.L. Consalvi, J.L. Torero, G. Legros, Broadband modulated absorption/emission technique to probe sooting flames: implementation, validation, and limitations, Proc. Combust. Inst. 37(2019), 3959-3966.

[27] A. Guibaud, J.M. Citerne, J.L. Consalvi, O. Fujita,J.L. Torero,G. Legros, Experimental evaluation of flame radiative feedback: methodology and application to opposed flame spread over coated wires in microgravity, Fire Tech. 56 (2020), 185-207.

[28] A. Guibaud, J.L. Consalvi, J.M. Orlac'h, J.M. Citerne, G. Legros, Soot production and radiative heat transfer in opposed flame spread over a polyethylene insulated wire in microgravity, Fire Tech. 56 (2020), 287314.

[29] G.H. Markstein, J. De Ris, Radiant emission and absorption by laminar ethylene and propylene diffusion flame, Proc. Combust. Inst. 20 (1984), 1637-1646. 
[30] T.L. B. Yelverton, W.L. Roberts, Effect of dilution, pressure, and velocity on smoke point in laminar jet flames, Combust. Sci. Technol. 180 (2008), 1334-1346.

[31] J. Bonnety, A. Guibaud, R. Jalain, A. Matynia, J.-L. Consalvi, F. Liu, G. Legros, Probing the local radiative quenching during the transition from a non-smoking to a smoking laminar coflow ethylene/air nonpremixed flame, Combust. Flame 203 (2019), 120-129.

[32] A.E Karatas, Ö.L. Gülder, Soot formation in high pressure laminar diffusion flames, Prog. Energy Combust. Sci. 38 (2012), 818-845.

[33] I. Glassman, Soot formation in combustion processes, Proc. Combust. Inst. 22 (1989), 295-311.

[34] T. Panagiotou, Y. Levendis, M. Delichatsios, Measurements of particle flame temperatures using three-color optical pyrometry, Combust. Flame 104 (1996), 272-287.

[35] T.P. Jenkins, R.K. Hanson, Soot pyrometry using modulated absorption/emission, Combust. Flame 126 (2001), 1669-1679.

[36] Y. Kobayashi, Y. Konno, X. Huang, S. Nakaya, M. Tsue, N. Hashimoto, O. Fujita, C. Fernandez-Pello, Effect of insulation melting and dripping on opposed flame spread over laboratory simulated electrical wires, Fire Safety J. 95 (2018), 1-10.

[37] G. Legros, Q. Wang, J. Bonnety, M. Kashif, C. Morin, J. -L. Consalvi, F. Liu, Simultaneous soot temperature and volume fraction measure- 
ments in axis-symmetric flames by a two-dimensional modulated absorption/emission technique, Combust. Flame 162 (2015), 2705-2719.

[38] R. Demarco, F. Nmira, J. L. Consalvi, Influence of thermal radiation on soot production in laminar axisymmetric diffusion flames, J. of Quant. Spect. Rad. Trans. 120 (2013), 52-69.

[39] M. F. Modest, Radiative heat transfer, Academic press (2013).

[40] H. -C. Chang, T. T. Charalampopoulos, Determination of the wavelength dependence of refractive indices of flame soot, Proc. Roy. Soc. London 430 (1990), 577-591.

[41] M. Kashif, J. Bonnety, P. Guibert, C. Morin, G. Legros, Soot volume fraction fields in unsteady axis-symmetric flames by continuous laser extinction technique, Optics Express 430 (2012), 28742-28751.

[42] S. L. Olson, P. V. Ferkul, J. S. T'ien, Near-limit flame spread over a thin solid fuel in microgravity, Proc. Combust. Inst. 22 (1989), 1213-1222.

[43] S. Rouvreau, P. Cordeiro, J. L. Torero, P. Joulain, Influence of g-jitter on a laminar boundary layer type diffusion flame, Proc. Combust. Inst. 30 (2005), 519-526.

[44] M. Nagachi, F. Mitsui, J.M. Citerne, H. Dutilleul, A. Guibaud, G. Jomaas, G. Legros, N. Hashimoto, O. Fujita, Effect of flow direction on the extinction limit for flame spread over wire insulation in microgravity, Int. Conf. Env. Sys. 47 (2017). 
[45] S.J. Lim, M. Kim, J. Park, O. Fujita, S. Chung, Flame spread over electrical wire with AC electric fields: Internal circulation, fuel vaporjet, spread rate acceleration, and molten insulator dripping, Combust. Flame 162 (2015), 1167-1175.

[46] J. Contreras, J. L. Consalvi, A. Fuentes, Oxygen index effect on the structure of a laminar boundary layer diffusion flame in a reduced gravity environment, Proc. Combust. Inst. 36 (2017), 3237-3245.

[47] G. Legros, J.L. Torero, Phenomenological model of soot production inside a non-buoyant laminar diffusion flame, Proc. Combust. Inst. 35 (2015), 2545-2553.

[48] Y. Konno, N. Hashimoto, O. Fujita, Downward flame spreading over electric wire under various oxygen concentrations, Proc. Combust. Inst. 37 (2019), 3817-3824.

[49] M.A. Delichatsios, Creeping flame spread: energy balance and application to practical materials, Int. Symp. Combust. 26 (1996), 1495-1503.

[50] J. de Ris, Spread of a laminar diffusion flame, Int. Symp. Combust. 12 (1969), 241-252.

[51] S. McAllister, J. Y. Chen, A. C. Fernandez-Pello, Fundamentals of Combustion Processes, Springer, New York, 2011.

[52] L. L. McCrain, W. L. Roberts, Measurements of the soot volume field in laminar diffusion flames at elevated pressures, Combust. Flame 140 (2005), 60-69. 
[53] K. A. Thomson, O. L. Gülder, E. J. Weckman, R. A. Fraser, G. J. Smallwood, D. R. Snelling, Soot concentration and temperature measurements in co-annular, nonpremixed $\mathrm{CH} 4 /$ air laminar flames at pressures up to $4 \mathrm{MPa}$, Combust. Flame 140 (2005), 222-232.

[54] D. S. Bento, K. A. Thomson, O. L. Gülder, Soot formation and temperature field structure in laminar propane-air diffusion flames at elevated pressures, Combust. Flame 145 (2006), 765-778.

[55] P. M. Mandatori, O. L. Gülder, Soot formation in laminar ethane diffusion flames at pressures from 0.2 to $3.3 \mathrm{MPa}$, Proc. Combust. Inst. 33 (2011), 577-584.

[56] J.J. Park, K. Park, J.-W. Park, D.C. Kim, Characteristics of LDPE Pyrolysis, Chem. Eng 19 (2002), 658-662.

[57] S. Lovett, F. Berruti, L. A. Behie, Ultrapyrolytic upgrading of plastic wastes and plastics/heavy oil mixtures to valuable light gas products, Ind. Eng. Chem. Res. 36 (1997), 4436-4444.

[58] H. F. Calcote, D. M. Manos, Effect of molecular structure on incipient soot formation, Combust. Flame 49 (1983), 289-304.

[59] C. S. McEnally, L. D. Pfefferle, Improved sooting tendency measurements for aromatic hydrocarbons and their implications for naphthalene formation pathways, Combust. Flame 148 (2007), 210-222.

[60] M. J. Hurley, D. T. Gottuk, J. R. Hall Jr, K. Harada, E. D. Kuligowski, M. Puchovsky, J. M. Watts Jr, C. J. Wieczorek, SFPE handbook of fire protection engineering, Springer (2015), 210-222. 
[61] S. Takahashi, H. Takeuchi, H. Ito, Y. Nakamura, O. Fujita, Study on unsteady molten insulation volume change during flame spreading over wire insulation in microgravity, Proc. Combust. Inst. 34 (2013), 26572664 .

[62] P. Andreussi, B. Barbieri, L. Petarca, Boundary layer burning of fuel surfaces: the soot field, Combust. Sci. Tech. 49 (1986), 123 - 141.

[63] M. D. Smooke, M. B. Long, B. C. Connelly, M. B. Colket, R. J. Hall, Soot formation in laminar diffusion flames, Combust. Flame 143 (2005), 613-628.

[64] G. Legros, A. Fuentes, S. Rouvreau, P. Joulain, B. Porterie, J.L. Torero, Transport mechanisms controlling soot production inside a non-buoyant laminar diffusion flame, Proc. Combust. Inst. 32 (2009), 2461-2470.

[65] J. Contreras, J.L. Consalvi, A. Fuentes, Numerical simulations of microgravity ethylene/air laminar boundary layer diffusion flames, Combust. Flame 143 (2005), 613-628.

[66] A.S. Luyt, J.A. Molefi, H. Krump, Thermal, mechanical and electrical properties of copper powder filled low-density and linear low-density polyethylene composites, Polymer Deg. and Stab. 91 (2006), 1629-1636.

[67] R.J. Santoro, H.G. Semerjian, Soot formation in diffusion flames: flow rate, fuel species and temperature effects, Int. Symp. Combust. 20 (1985), 997-1006.

[68] M. Kikuchi, O. Fujita, S. Takahashi, A. Ito, H. Torikai, Y. Nakamura, S.L. Olson, Overview of the "solid combustion" experiment in the 
Japanese experiment module "Kibo" on the International Space Station, Int. Conf. Env. Sys. 25 (2015). 